\title{
A Novel Hybrid Multiple Attribute Decision-Making Approach sfor Outsourcing Sustainable Reverse Logistics
}

\author{
Navid Zarbakhshnia ${ }^{1}$, Yong $\mathrm{Wu}^{2, *}$, Kannan Govindan ${ }^{3}$, Hamed Soleimani ${ }^{3}$
}

1. Young Researchers and Elites Club, Qazvin Branch, Islamic Azad University, Qazvin, Iran. (Navid_z11@yahoo.com)

2. Department of Business Strategy and Innovation, Griffith University, Gold Coast Campus, QLD 4222, Australia. (yong.wu@griffith.edu.au)

3. Center for Sustainable Supply Chain Engineering, Department of Technology and Innovation, University of Southern Denmark, Campusvej 55, DK-5230, Odense M, Denmark. (kgov@iti.sdu.dk,hsol@iti.sdu.dk)

\begin{abstract}
In this paper, we propose a novel hybrid multiple attribute decision-making (MADM) approach, which includes fuzzy analytic hierarchy process (fuzzy AHP) and gray multi-objective optimization by ratio analysis (MOORA-G). By using fuzzy and gray numbers, we successfully deal with the qualitative and uncertain inputs that often arise from real-world decision-making process. We adopt this hybrid approach to take the advantages offered by both methods, and designate the former for weighting the considered criteria, and the latter for ranking the alternatives. To demonstrate the performance of the proposed hybrid approach, we apply it to a case study on the selection of third-party reverse logistics providers (3PRLPs) for a car parts manufacturing company and benchmark it with the MOORA method. The outcome of this study indicates that our proposed approach can offer more viable performance when facing qualitative data and input uncertainties, and consequently, lends itself to a wider range of applications.
\end{abstract}

\section{Keywords}

Sustainable Reverse Logistics; Third-Party Reverse Logistics Provider (3PRLP); Fuzzy Analytic Hierarchy Process (Fuzzy AHP); Gray Multi-Objective Optimization by Ratio Analysis (MOORA-G); Multiple Attribute Decision-Making (MADM).

\section{Introduction}

Reverse logistics is the scheduling and planning for the backward flow of products, to be more specific second-hand goods, from customers and consumers to suppliers and manufacturers for the purpose of several activities such as repairing, remanufacturing, recycling, disposal and so on (Govindan et al., 2018). Reverse logistics could help obtain a viable and suitable balance between economic and environmental matters, in such a way that it not only brings profit with second-hand goods refurbishment but also protects the environment with recycling and proper disposal (Peretti et al., 2015; Zarbakhshnia et al., 2019). According to Rogers and Tibben-Lembke (1999), "reverse logistics is the trend of design, schedule, planning, controlling and warehousing and also

* Corresponding author. 
information for returned products in reverse flow of classical supply chain in order to recover value and get the competitive advantage".

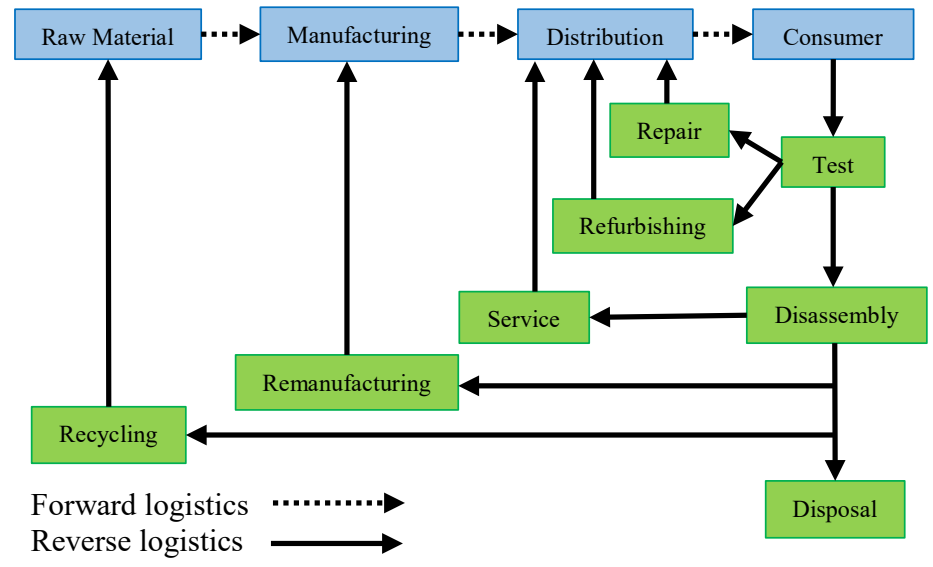

Figure 1. A framework for forward and reverse logistics (Soleimani and Govindan, 2014).

Figure 1 demonstrates the flows of physical goods for forward and reverse logistics in supply chains. There are a number of reasons which make reverse logistics a key strategy in each supply chain. First of all, it should be stressed that due to lack of raw materials and their increasing costs/prices, many companies have turned their faces to reverse logistics activities these days (John et al., 2018). Secondly, with escalated environmental consciousness of consumers and government officials, legislation was proposed or enforced in the past two decades to protect the environment from potential damages. Hence, the majority of firms are forced to choose strategies to not only bring economic benefits but also protect the resources of raw materials as the environment (Govindan and Soleimani, 2017). Lastly, sustainable development covers the three dimensions of economic, environmental and social matters. Reverse logistics operations, while a challenging task, naturally cover the three dimensions of sustainability (See Figure 2) (Garetti and Taisch, 2012; Zarbakhshnia and Jaghdani, 2018).

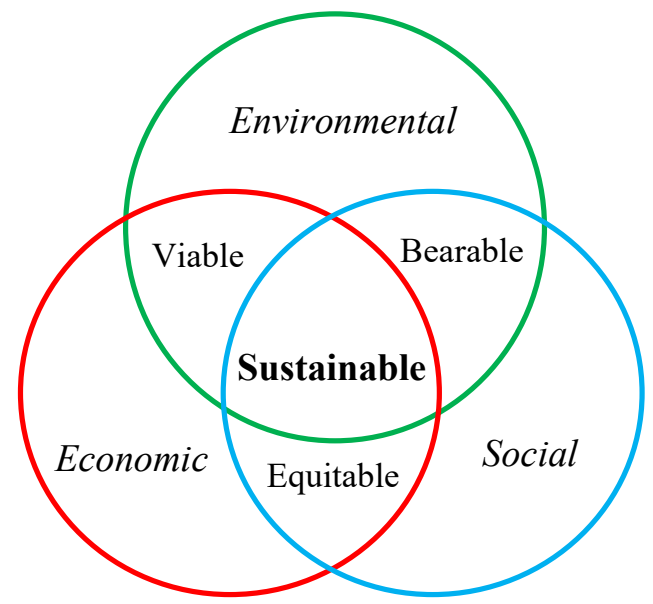

Figure 2. The three aspects of sustainability (Garetti and Taisch, 2012). 
Planning and designing a reverse logistics network is a complicated and complex task for any organization, as there are generally a large set of criteria to be considered, some of which are often difficult to quantify. Consequently, many companies choose to outsource these logistics activities to specialized third-party providers, so as to reduce the costs and elevate the quality of recovery of delivered second-hand products to create competitive advantages (Govindan et al., 2012). Therefore, it is crucial for companies to select the best available third-party reverse logistics provider (3PRLP) by considering the desired selection criteria. Multiple attribute decision-making (MADM) techniques, which carry out the selection process by evaluating several criteria in various dimensions simultaneously, have appeared to be promising for this task (Mavi et al., 2017).

In this paper, we design a novel hybrid MADM model using fuzzy analytic hierarchy process (fuzzy AHP) and gray multi-objective optimization by ratio analysis (MOORA-G). Fuzzy AHP is a method that considers the relation and effect of criteria with the alternatives. This feature makes it a suitable candidate for determining the weights of selection criteria to obtain the amount of influence of each criterion in the decision process. The MOORA method is a multi-objective optimization approach for ranking discrete alternatives. As the name suggests, the technique refers to a matrix of responses of alternatives in order to find out which ratios should be applied to them. The ratios are calculated by taking the square root of the sum of squared responses as the denominator, which subsequently leads to dimensionless ratios between zero and one for all the alternatives. In this sense, the MOORA method addresses the four sections in each decisionmaking problem, e.g., the options for each objective, normalization, optimization, and the importance of each alternative (Majumder and Maity, 2017), and makes the decision-making process a reliable one. We also apply gray numbers in the MOORA method to address the challenge brought by uncertain and qualitative inputs. Overall, the results obtained from the fuzzy AHP are applied to the normalized decision matrix of the MOORA-G to derive the ultimate ranking of different alternatives. We adopt this hybrid approach to take the advantages offered by both methods, and designate the former for weighting the considered criteria, and the latter for ranking the 3PRLPs (alternatives).

The remainder of this paper is organized as follows: Section 2 presents the literature review and identifies the existing gaps in outsourcing reverse logistics activities by utilizing MADM techniques. Section 3 explains how the hybrid MADM method works. In Section 4, we apply the hybrid approach to a case study on the selection of 3PRLPs for a car parts manufacturing company, conduct benchmark comparisons, and discuss the results. Section 5 offers managerial implications of this study. The paper is concluded in Section 6.

\section{Literature Review}

The nature of reverse logistics makes it a sustainable endeavor (Turki et al., 2018). Reverse logistics covers all the three dimensions of sustainability by reducing costs as an economic part, protecting the environment with disposal, recycling, and other processes as an environmental part, and finally guarding natural resources for next generations as a social part (Li et al., 2017; Prajapati et al., 2018; Yu and Solvang, 2018). As a result, reverse logistics is becoming an inevitable strategy for manufacturing companies in the current era (Agrawal et al., 2016; Kuşakc1 et al., 2019). Yet, using this strategy needs a professional support team, including designing and planning a strong 
network as well as repair and maintenance experts to keep the network active, due to the complexities involved in reverse logistics operations (Li et al., 2018a; Tian et al., 2019). Consequently, most manufacturers prefer to outsource their reverse logistics activities to professional service providers (Tosarkani and Amin, 2018), which at the same time is costeffective for them (Mahmoudzadeh et al., 2013).

In the outsourcing process, one difficulty is finding a qualified service provider (Tavana et al., 2016b). There are two influencing factors: the first one is the proposed evaluation approach, and the second one is the set of criteria to be considered by the proposed evaluation methodology (Zhang et al., 2012). Often, the criteria set may influence the proposed method. For instance, if some of the determined criteria have qualitative content, the proposed method will need to be able to deal with the qualitative inputs and turn them into quantitative criteria (Bianchini, 2018). Moreover, as each criterion has different value and impact on the selection process, the evaluation method should include a weighting method to determine the proper contribution of each criterion on the selection process. In terms of criteria, there are a plethora of criteria in the literature and practice. Companies will need to consider a set of criteria based on their manufactured products and conditions (Perçin, 2019).

Researchers have applied and considered several approaches and criteria in order to select the best 3PRLP. They have tried to select and expand suitable methods to improve the quality of the ranking process, which directly helped decision-makers for viable decision-making, and dealt with uncertainty and uncertain criteria as well. Furthermore, having a set of appropriate criteria is one of the most important points in the decision-making process, in a way that they could significantly affect the ranking of alternatives when including or excluding certain criteria (Bouzon et al., 2016). Therefore, in this study, we try to evaluate previous studies to establish a viable set of criteria, alongside the MADM ranking approach development. Tables 1, 2, and 3 present a summary of the literature review on outsourcing the reverse logistics activities (3PRLP selection and evaluation).

Table 1 summarizes the methods used for reverse logistics outsourcing decision-making in papers published from the year 2009 to 2019. It can be observed that AHP is a common method used for weighting criteria, especially for 3PRLP selection. However, it is evident that the MOORA method has almost been missed in the literature of reverse logistics outsourcing decisionmaking, even though it is one of the latest MADM methods. Indeed, the summary of MOORA applications in Table 2, which lists different applications of the MOORA method in terms of study years, environments, application areas, and approaches, confirms the observation from Table 1. The results in Table 2 demonstrate that the MOORA method is a multi-tasking and flexible MADM method, in such a way that it was not only used for selection, measurement, prediction and optimization, and comparison problems, but also applied to various industries and applications. Such a multiplicity of applications proves that the MOORA method has many practical values. Yet, there is a paucity of applications in the areas of logistics management and 3PRLP selections. 
Table 1. Summary of the applied methods to outsource reverse logistics activities.

\begin{tabular}{|c|c|c|c|c|c|c|c|c|c|c|c|c|}
\hline \multirow[b]{3}{*}{ Researchers } & \multicolumn{12}{|c|}{ Methods } \\
\hline & \multirow[b]{2}{*}{$\frac{\mathrm{O}}{\mathrm{Z}}$} & \multirow[b]{2}{*}{ 文 } & \multirow[b]{2}{*}{$\underset{\mathbb{1}}{\mathbb{1}}$} & \multirow[b]{2}{*}{ 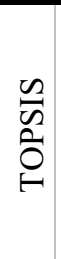 } & \multirow[b]{2}{*}{$\begin{array}{l}\text { oै } \\
\text { y } \\
\Rightarrow\end{array}$} & \multirow[b]{2}{*}{$\begin{array}{l}\frac{n}{d} \\
\frac{\pi}{0} \\
0\end{array}$} & \multirow{2}{*}{ 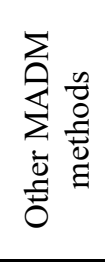 } & \multirow{2}{*}{ 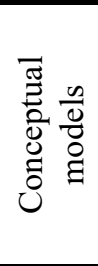 } & \multirow{2}{*}{ 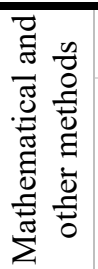 } & \multicolumn{3}{|c|}{ MOORA } \\
\hline & & & & & & & & & & Uี & $\underset{\text { 胥 }}{\stackrel{N}{N}}$ & $\overrightarrow{\overparen{b}}$ \\
\hline Farzipoor Saen (2009) & & &.$/$ & & & & & & & & & \\
\hline Kannan et al. (2009) & & & & $x$ & & & & & & & & \\
\hline Cheng and Lee (2010) & & $\checkmark$ & & & & & & & & & & \\
\hline Saen (2010) & & & $\checkmark$ & & & & & & & & & \\
\hline Azadi and Saen (2011) & & & $\checkmark$ & & & & & & & & & \\
\hline Chiu et al. (2011) & & & & & & & & & $\checkmark$ & & & \\
\hline Sasikumar and Haq (2011) & & & & & & & $\checkmark$ & & & & & \\
\hline Govindan et al. (2012) & & & & & & & & & $\checkmark$ & & & \\
\hline Wang and Zhu (2012) & & & & & & & & & $\checkmark$ & & & \\
\hline Govindan et al. (2013) & & $\checkmark$ & & & & & & & & & & \\
\hline Samantra et al. (2013) & & & & & $\checkmark$ & & & & & & & \\
\hline Zareinejad et al. (2013) & & $\checkmark$ & & & & & & & & & & \\
\hline Jayant et al. (2014) & $\checkmark$ & & & $\checkmark$ & & & & & & & & \\
\hline Kafa et al. (2014) & & & & & & & & & & & & \\
\hline Suyabatmaz et al. (2014) & & & & & & & & & $\gamma$ & & & \\
\hline Da Silveira Guimarães and Salomon. (2015) & & $\checkmark$ & & & & & & & & & & \\
\hline Guarnieri et al. (2015) & & $\checkmark$ & & & & & $\checkmark$ & & & & & \\
\hline Hsueh and Lin (2015) & & $\checkmark$ & & & & & $v$ & & & & & \\
\hline Momeni et al. (2015) & & & $\checkmark$ & & & & & & & & & \\
\hline Masten and Kim (2015) & & & & & & & & & & & & \\
\hline Awasthi and Kannan (2016) & & & & & $\checkmark$ & & & & & & & \\
\hline Prakash and Barua (2016a) & $\checkmark$ & & & & $\checkmark$ & & & & & & & \\
\hline Tavana et al. (2016a) & & $\checkmark$ & & & & & & $\checkmark$ & & & & \\
\hline Tavana et al. (2016b) & $\checkmark$ & & & & & & & & & & & \\
\hline Govindan et al. (2017) & $\checkmark$ & & & $\checkmark$ & & & & & & & & \\
\hline Ilgin (2017) & & & & s & & & & & & & & \\
\hline Jain and Khan (2017) & $\checkmark$ & & & & & & & & & & & \\
\hline Kannan et al. (2017) & & & & & & & & & $\checkmark$ & & & \\
\hline Keshavarz Ghorabaee et al. (2017) & & & & & & & $\checkmark$ & & & & & \\
\hline Mavi et al. (2017) & & & & & & & & & & & $\checkmark$ & \\
\hline Li et al. (2018a) & & & & & & & & & $\checkmark$ & & & \\
\hline Li et al. (2018b) & & & & & & & $\checkmark$ & & & & & \\
\hline Mavi et al. (2018) & & & & & & $\checkmark$ & & & & & & \\
\hline Zarbakhshnia et al. (2018) & & & & & & $\checkmark$ & & & & & & \\
\hline Govindan et al. (2019) & & & & & $\checkmark$ & & & & & & & \\
\hline Liu et al. (2019) & & & & & & & & & $\checkmark$ & & & \\
\hline Bai and Sarkis (2019) & & & & $\checkmark$ & $\checkmark$ & & & & & & & \\
\hline Total (Times of usage) & 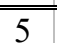 & 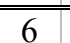 & 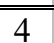 & $\overline{5}$ & $\overline{5}$ & $\overline{c 1}$ & $\overline{\overline{5}}$ & $\overline{11}$ & $\overline{\overline{7}}$ & 0 & $\overline{c 1}$ & $\overline{00}$ \\
\hline
\end{tabular}


Table. 2. Classified literature review of the MOORA method.

\begin{tabular}{|c|c|c|c|c|}
\hline No. & Study & Environment & Application areas & Approach \\
\hline 1 & Brauers and Zavadskas (2006) & Certain & Privatization project selection & Economic \\
\hline 2 & Brauers et al. (2008) & Certain & Road design selection & Economic \\
\hline 3 & Gadakh (2010) & Certain & Milling process parameter selection & Economic \\
\hline 4 & Chakraborty (2011) & Certain & Manufacturing environment selection & Economic \\
\hline 5 & Archana and Sujatha (2012) & Fuzzy & Network connection selection & Economic \\
\hline 6 & Das et al. (2012) & Certain & Performance measurement of technical institutions & Economic \\
\hline 7 & El-Santawy and El-Dean (2012) & Certain & Consulting Firm selection & Economic \\
\hline 8 & Karande and Chakraborty, (2012a) & Certain & Materials selection & Economic \\
\hline 9 & Karande and Chakraborty, (2012b) & Certain & Supplier selection & Economic \\
\hline 10 & Karande and Chakraborty, (2012c) & Fuzzy & ERP system selection & Economic \\
\hline 11 & El-Santawy and Ahmed (2012a) & Certain & Project selection & Economic \\
\hline 12 & El-Santawy and Ahmed (2012b) & Certain & Personnel training selection & Economic \\
\hline 13 & Brauers (2013) & Certain & Seaport planning & Economic \\
\hline 14 & Gorener et al. (2013) & Certain & Bank branch location selection & $\begin{array}{l}\text { Economic and } \\
\text { social }\end{array}$ \\
\hline 15 & Stanujkic (2013) & Fuzzy & Mining grinding circuit design selection & Environmental \\
\hline 16 & Tansel İç and Yıldırım (2013) & Certain & Theoretical & None \\
\hline 17 & Attri and Grover (2014) & Certain & Product design approach selection & Economic \\
\hline 18 & Ozcelik et al. (2014) & Fuzzy & Special education and rehabilitation center selection & $\begin{array}{l}\text { Economic and } \\
\text { social }\end{array}$ \\
\hline 19 & Akkaya et al. (2015) & Fuzzy & Industrial engineering sector selection & $\begin{array}{l}\text { Economic and } \\
\text { social }\end{array}$ \\
\hline 20 & Dincer (2015) & Fuzzy & Profit-based stock selection & Economic \\
\hline 21 & Pérez-Domínguez et al. (2015) & Fuzzy & Supplier selection & Economic \\
\hline 22 & Sarkar et al. (2015) & Certain & Non-traditional machine selection & Economic \\
\hline 23 & Kundakci (2016) & Certain & Automobile selection & Economic \\
\hline 24 & Matawale et al. (2016) & Fuzzy & Supplier selection & \\
\hline 25 & Önay (2016) & Certain & Life standards of the countries ranking & Sustainable \\
\hline 26 & Sahu et al. (2016) & Certain & CNC machine tool evaluation & Economic \\
\hline 27 & Siddiqui and Tyagi (2016) & Fuzzy & Ranking of software systems components & Economic \\
\hline 28 & Gupta et al. (2017) & Fuzzy & Measuring data distribution strategies & Economic \\
\hline 29 & Kalirasu et al. (2017) & Certain & Machinability performance measurement & Economic \\
\hline 30 & Majumder and Maity (2017) & Certain & Optimization of machining condition & Economic \\
\hline 31 & Mavi et al. (2017) & Fuzzy & 3PRLP selection & Sustainable \\
\hline 32 & Yüksel et al. (2017) & Certain & Comparing the performance of deposit banks & Economic \\
\hline 33 & Abdi (2018) & Certain & Hospital leanness assessment model & $\begin{array}{l}\text { Economic and } \\
\text { social }\end{array}$ \\
\hline 34 & Arabsheybani et al. (2018) & Fuzzy & Supplier selection & Sustainable \\
\hline 35 & Chand et al. (2018) & Certain & Analysis of green supply chain management issues & Environmental \\
\hline 36 & Dinçer et al. (2018) & Fuzzy & $\begin{array}{l}\text { Evaluation of effects on green supply chain } \\
\text { management }\end{array}$ & Environmental \\
\hline 37 & Majumder and Maity (2018) & Fuzzy & $\begin{array}{l}\text { Prediction and optimization of surface roughness and } \\
\text { micro-hardness }\end{array}$ & Economic \\
\hline 38 & Pérez-Domínguez et al. (2018) & Fuzzy & Packing supplier selection & Economic \\
\hline 39 & Ghoushchi et al. (2019) & Fuzzy & Prioritization of failures & Economic \\
\hline 40 & Zavadskas et al. (2019) & Certain & Energy ecological parameters selection & Environmental \\
\hline$\doteq \bar{\omega}$ & $\begin{array}{l}\text { Number of studies about logistics } \\
\text { management using MOORA }\end{array}$ & & 1 & \\
\hline
\end{tabular}


Number of studies with combined fuzzy and gray environment using MOORA

Number of studies with sustainable, risk, and safety using MOORA

This paper (2019)

\begin{tabular}{|l|}
\hline \multicolumn{1}{|c|}{0} \\
\hline $\begin{array}{l}\text { Combined } \\
\text { fuzzy and gray }\end{array}$ \\
\hline
\end{tabular}

\begin{tabular}{|l|l|} 
& \multicolumn{1}{c}{0} \\
3PRLP selection & $\begin{array}{l}\text { Sustainable, } \\
\text { Risk, and } \\
\text { Safety }\end{array}$ \\
\hline
\end{tabular}

The advantage of the MOORA method, in comparison with other MADM methods, is that it refers to a responses' matrix of alternatives to determine which alternative is the best regarding the ratios (Brauers and Zavadskas, 2009). Several of the other MADM methods, such as AHP, takes two alternatives at a time and compares their criteria one by one to develop a comparison matrix. Furthermore, the AHP technique computes the weights of criteria in the decision-making problems by using the pairwise comparison method for criteria. The weights of criteria play a key role in multi-attribute decision-making problems because each criterion may not contribute equally to choose the best alternative (Matawale et al., 2016). Therefore, creating the comparison matrices becomes a lengthy process. In the case of MOORA, all the alternatives are determined at the same time by giving scores in a decision matrix according to the criteria to discover the best alternative, which eliminates the lengthy computation part in comparison with MADM methods using pairwise comparisons (Sahu et al., 2014).

Amongst the other methods which use decision matrix, TOPSIS is the most similar technique to MOORA. Indeed, the MOORA method, like the TOPSIS method, utilizes vector normalization procedure to normalize the decision matrix (Kecek and Demirag, 2016; Wang et al., 2019). TOPSIS is a technique for order of preference by similarity to the ideal solution and computes the relative distance to the ideal solution, in such a way that the shortest geometric distance from the positive ideal solution and the longest geometric distance from the negative ideal solution represent the best and the worst alternatives respectively (dos Santos et al., 2019). Nonetheless, MOORA works on the basis of the ratio system approach and reference point approach which not only restricts the ratios as outcomes of the technique, but also keeps them under control. This means that the ratio of one alternative could not be so bigger than the others owing to the restricted ratios between zero and one, while there are differences among the ratios to indicate the importance of different alternatives (Mavi et al., 2017). Yet, those methods which use the decision matrix still need auxiliary approaches to weight the considered criteria prior to the process of ranking the alternatives (İç, 2019). That is the reason why they usually are combined with other methods as hybrid approaches.

In Table 3, the criteria considered in some recent publications for outsourcing the reverse logistics activities are listed. The table shows that earlier published papers only considered a few key criteria, while recent research has shifted to covering a more comprehensive set of criteria which led to rewarding results. Additionally, the majority of papers have been missing the safety and risk attributes, especially safety criterion, while they play a significant role in logistics management and outsourcing. In this paper, the criteria in Table 3 were presented to a panel of experts to determine their suitability to be listed as the selection criteria for the case company. The panel confirmed that the set was comprehensive, covered different aspects of the 3PRLP selection process, and recommended to use it as the final set. 
Table 3. Criteria considered for outsourcing the reverse logistics activities.

\begin{tabular}{|c|c|c|c|c|c|c|c|c|c|c|c|c|c|c|c|c|}
\hline \multirow[b]{2}{*}{ Dimensions } & \multirow[b]{2}{*}{ Sub-Criteria } & \multirow[b]{2}{*}{$\begin{array}{l}\text { 을 } \\
\text { E. } \\
\text { : }\end{array}$} & \multicolumn{14}{|c|}{ Author (Reference) } \\
\hline & & & 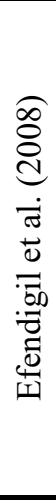 & 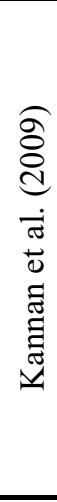 & 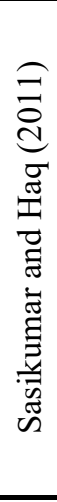 & 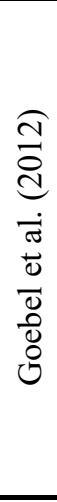 & 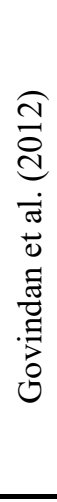 & 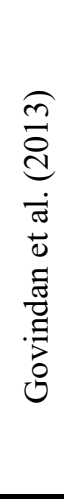 & 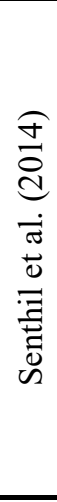 & 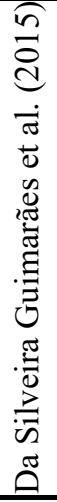 & 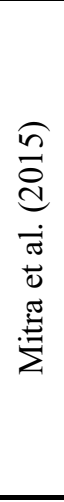 & 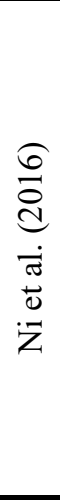 & 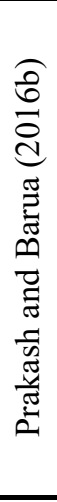 & 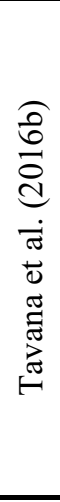 & 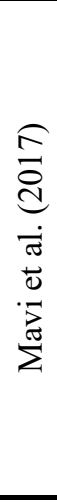 & 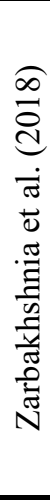 \\
\hline \multirow{6}{*}{ Economic $\left(C_{1}\right)$} & C1.1. Quality & Max & & $\checkmark$ & $\checkmark$ & & $\checkmark$ & & & & & & $\checkmark$ & $\checkmark$ & $\checkmark$ & $\checkmark$ \\
\hline & C1.2. Cost & Min & $\checkmark$ & $\checkmark$ & $\checkmark$ & & $\checkmark$ & & & $\checkmark$ & & & $\checkmark$ & $\checkmark$ & $\checkmark$ & $\checkmark$ \\
\hline & C1.3. Lead time & Min & $\checkmark$ & $\checkmark$ & & & & & $\checkmark$ & & & & & $\checkmark$ & $\checkmark$ & $\checkmark$ \\
\hline & C1.4. Delivery & Max & $\checkmark$ & $\checkmark$ & $\checkmark$ & & $\checkmark$ & & & & & & $\checkmark$ & & $\checkmark$ & $\checkmark$ \\
\hline & C1.5. Services & Max & & & & & $\checkmark$ & & & & & & $\checkmark$ & $\checkmark$ & $\checkmark$ & $\checkmark$ \\
\hline & $\begin{array}{l}\text { C1.6. Capability Of } \\
\text { R \& D }\end{array}$ & $\operatorname{Max}$ & & & & $\checkmark$ & & & & & & $\checkmark$ & & & & \\
\hline \multirow{8}{*}{$\begin{array}{c}\text { Environmental } \\
\left(\mathrm{C}_{2}\right)\end{array}$} & C2.1. Green Design & Max & & & & & & $\checkmark$ & & & & & & & $\checkmark$ & $\checkmark$ \\
\hline & C2.2. Reuse & Max & & & $\checkmark$ & $\checkmark$ & $\checkmark$ & & & & & & $\checkmark$ & $\checkmark$ & $\checkmark$ & $\checkmark$ \\
\hline & C2.3. Remanufacture & $\operatorname{Max}$ & & & $\checkmark$ & $\checkmark$ & $\checkmark$ & & & & & & $\checkmark$ & $\checkmark$ & $\checkmark$ & $\checkmark$ \\
\hline & C2.4. Refurbish & Max & & & $\checkmark$ & & & & $\checkmark$ & & & & & $\checkmark$ & & \\
\hline & C2.5. Recycle & Max & & & $\checkmark$ & & $\checkmark$ & $\checkmark$ & & $\checkmark$ & & & $\checkmark$ & $\checkmark$ & $\checkmark$ & $\checkmark$ \\
\hline & C2.6. Disposal & Max & & & $\checkmark$ & & $\checkmark$ & & & & & & $\checkmark$ & $\checkmark$ & $\checkmark$ & $\checkmark$ \\
\hline & C2.7. Air Emissions & Min & & & & & & & & $\checkmark$ & & & & & & \\
\hline & $\begin{array}{l}\text { C2.8. Green } \\
\text { Packaging }\end{array}$ & Max & & & $\checkmark$ & & & & & $\checkmark$ & & & $\checkmark$ & & & \\
\hline \multirow{5}{*}{ Social $\left(C_{3}\right)$} & C3.1 Health & Max & & & & & & $\checkmark$ & & & & & & & $\checkmark$ & $\checkmark$ \\
\hline & $\begin{array}{l}\text { C3.2. Flexible } \\
\text { Working } \\
\text { Arrangements }\end{array}$ & Max & & & & & & $\checkmark$ & & & & & $\checkmark$ & & & \\
\hline & $\begin{array}{l}\text { C3.3 Voice of } \\
\text { Customer }\end{array}$ & Max & $\checkmark$ & & & & $\checkmark$ & & & & & & & & $\checkmark$ & $\checkmark$ \\
\hline & $\begin{array}{l}\text { C3.4 Respect For } \\
\text { The Policy }\end{array}$ & Max & & & & $\checkmark$ & $\checkmark$ & & & $\checkmark$ & & & & & $\checkmark$ & $\checkmark$ \\
\hline & C3.5. Reputation & $\operatorname{Max}$ & $\checkmark$ & & & & & & & $\checkmark$ & & & & & & \\
\hline \multirow{4}{*}{$\begin{array}{c}\text { Risk and } \\
\text { Safety }\left(C_{4}\right)\end{array}$} & C4.1 Operational risk & Min & & & & & & & & & $\checkmark$ & & $\checkmark$ & & $\checkmark$ & $\checkmark$ \\
\hline & $\begin{array}{l}\text { C4.2. Organizational } \\
\text { Risk }\end{array}$ & Min & & & & & & & & & $\checkmark$ & & & & $\checkmark$ & \\
\hline & C4.3 Financial risk & Min & & & & & & & & & & $\checkmark$ & $\checkmark$ & & $\checkmark$ & $\checkmark$ \\
\hline & C4.4. Safety & $\operatorname{Max}$ & & & & & $\checkmark$ & & & & $\checkmark$ & & & & & \\
\hline
\end{tabular}


The main contribution of this paper is as follows:

- The MOORA technique is developed, for the first time, to handle gray relations. This contributes to the area of applying MOORA technique from a theoretical development perspective.

- Risk and safety criteria are evaluated within the three aspects of sustainability.

- Applicability of the proposed hybrid approach is illustrated with a case study. As demonstrated in the literature review, this successfully addresses the gap of applying the MOORA method in the field of logistics management.

\section{Hybrid MADM Approach}

In this section, we present the hybrid MADM approach. The approach first utilizes fuzzy AHP to weight the criteria in the three sustainability dimensions and incorporates risk and safety factors. It then extends the MOORA-G method with gray relations to select the sustainable 3PRLP (see Figure 3).

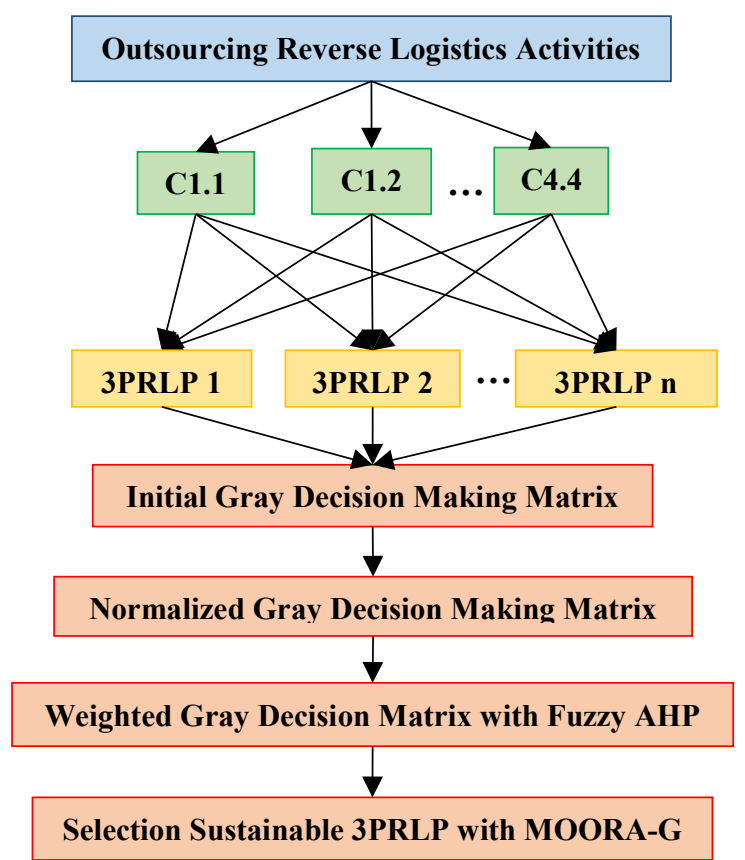

Figure 3. The hierarchy process of outsourcing reverse logistics activities.

Figure 3 denotes the hierarchy process for outsourcing reverse logistics activities. First, an initial gray decision-making matrix is constructed. The matrix is subsequently normalized and fuzzy AHP method is applied to compute the criteria weights. Based on the weighted gray decision matrix, MOORA-G is used to rank all the 3PRLPs. The linguistic variables for both fuzzy AHP and MOORA-G are turned into quantifiable criteria based on the conversions listed in Table 4. 
Table 4. Fuzzy/gray scales and alterations for fuzzy/gray membership functions.

\begin{tabular}{|l|c|c|l|l|}
\hline \multicolumn{2}{|l|}{$\begin{array}{l}\text { Fuzzy numbers for weights of the factors (Aghdaie et al., } \\
\text { 2013) }\end{array}$} & \multicolumn{2}{l|}{$\begin{array}{l}\text { Gray numbers for rating } \\
\text { alternatives (Li et al., 2007) }\end{array}$} \\
\hline $\begin{array}{l}\text { Linguistic scale for } \\
\text { importance }\end{array}$ & $\begin{array}{l}\text { Triangular fuzzy } \\
\text { scales }(\boldsymbol{l}, \boldsymbol{m}, \boldsymbol{u})\end{array}$ & $\begin{array}{l}\text { Fuzzy numbers } \\
\text { for fuzzy AHP }\end{array}$ & $\begin{array}{l}\text { Linguistic variables } \\
\text { for rating criteria }\end{array}$ & $\begin{array}{l}\text { Gray } \\
\text { numbers }\end{array}$ \\
\hline Just equal & $(1,1,1)$ & $\tilde{0}$ & Very poor (VP) & {$[0 ; 1]$} \\
\hline Equal importance & $(1,1,3)$ & $\tilde{1}$ & Poor (P) & {$[1 ; 3]$} \\
\hline $\begin{array}{l}\text { Weak importance of one } \\
\text { over another }\end{array}$ & $(1,3,5)$ & $\tilde{2}$ & Medium poor (MP) & {$[3 ; 4]$} \\
\hline $\begin{array}{l}\text { Essential or strong } \\
\text { importance }\end{array}$ & $(3,5,7)$ & $\tilde{3}$ & Fair (F) & {$[4 ; 5]$} \\
\hline Strong importance & $(5,7,9)$ & $\tilde{4}$ & Medium good (MG) & {$[5 ; 6]$} \\
\hline Very strong importance & $(7,9,9)$ & $\tilde{5}$ & Good (G) & {$[6 ; 9]$} \\
\hline Extremely preferred & $(9,9,9)$ & $\tilde{6}$ & Very good (VG) & {$[9 ; 10]$} \\
\hline
\end{tabular}

The parameter and variables used for the proposed hybrid approach are listed as follows:

Parameters:

$m \quad$ Number of alternatives, indexed by $k$.

$n \quad$ Total number of factors, indexed by $i, j$.

$g \quad$ The number of benefit factors.

$q \quad$ Number of experts, indexed by $h$.

Variables:

$\tilde{a}_{i j}^{(h)} \quad$ The value of the pairwise comparison between factors $i$ and $j$ by expert $h$.

$\tilde{d}_{i j} \quad$ The geometric mean of fuzzy comparison value between factors $i$ and $j$.

$\widetilde{M}_{i} \quad$ The value of fuzzy extent for factor $i$.

$\widetilde{w}_{i}, \widetilde{w}_{j} \quad$ The value of fuzzy synthetic extent (fuzzy weights) with respect to the fuzzy extent value of dimensions for each criterion.

$X \quad$ The initial gray decision matrix in MOORA-G.

$x_{k j}, u_{k j} \quad$ The lower and upper limits of a gray number for alternative $k$ for factor $j$.

$\bar{X} \quad$ The normalized gray decision-making matrix.

$\bar{x}_{k j}, \bar{u}_{k j} \quad$ The normalized lower and upper limits of a gray number for alternative $k$ for factor $j$.

$\hat{X} \quad$ The weighted normalized gray decision-making matrix.

$\hat{x}_{k j}, \hat{u}_{k j} \quad$ The weighted normalized lower and upper limits of a gray number for alternative $k$ for factor $j$. 
$\hat{y}_{k} \quad$ The normalized performance value for alternative $k$.

$B N G P_{k}\left(y_{k}\right)$ The best non-gray performance value for alternative $k$.

\subsection{Fuzzy AHP}

Saaty (1980) developed the AHP method for the first time and Van Laarhoven and Pedrycz (1983) applied fuzzy logic to AHP to deal with uncertainty. The AHP method can be used for both ranking alternatives and weighting criteria in MADM problems based on a pairwise comparison approach to organize the comparison matrix. However, it should be mentioned that in terms of ranking and selection of alternatives, the AHP method takes a lot time in its calculation process due to the pairwise comparisons. On the contrary, in the weighting part, since AHP utilizes pairwise comparison, it would be a more efficient approach than the other weighting approaches to calculate unique weights for each of the determined criteria. This owes to the fact that in pairwise comparison, each pair of the criteria are evaluated and the relations between them are considered. Thus, AHP is usually used to compute weights of criteria and combined with other MADM methods to structure hybrid models. Fuzzy AHP, as the name suggests, is capable of dealing with qualitative and uncertain inputs. We use the basic mathematical operations on triangular fuzzy numbers defined in literature (e.g., Santos and Camargo, 2010) to facilitate the handling of fuzzy numbers in this paper. Given fuzzy numbers $A_{1}=\left(l_{1}, m_{1}, u_{1}\right)$, where $l_{1} \leq m_{1} \leq u_{1}$, and $A_{2}=$ $\left(l_{2}, m_{2}, u_{2}\right)$, where $l_{2} \leq m_{2} \leq u_{2}$, the fuzzy addition, subtraction, multiplication and division are conducted as follows:

- Fuzzy addition:

$$
A_{1} \oplus A_{2}=\left(l_{1}+l_{2}, m_{1}+m_{2}, u_{1}+u_{2}\right)
$$

- Fuzzy subtraction:

$$
A_{1} \ominus A_{2}=\left(l_{1}-u_{2}, m_{1}-m_{2}, u_{1}-l_{2}\right)
$$

- Fuzzy multiplication:

$$
A_{1} \otimes A_{2}=\left(l_{1} l_{2}, m_{1} m_{2}, u_{1} u_{2}\right)
$$

- Fuzzy division:

$$
A_{1} \oslash A_{2}=\left(l_{1} / u_{2}, m_{1} / m_{2}, u_{1} / l_{2}\right)
$$

With fuzzy number operations defined, the following steps list the fuzzy AHP approach:

Step 1. Organize pairwise comparison matrices for all the criteria in each dimension of the hierarchy structure. It means that each of the criteria of the considered dimension should appear on both the column and the row of each matrix, to establish the pairwise comparison.

Step 2. Allocate linguistic scales and triangular fuzzy numbers from Table 4 to the pairwise comparison matrices to demonstrate which dimension is more significant, as shown in Eq. (1). In this step, the usual crisp pairwise comparison matrices are turned into fuzzy pairwise comparison matrices not only to facilitate capturingideas from the experts in the survey questionnaire, but also to deal with uncertainty of the qualitative criteria. 


$$
\tilde{A}^{(h)}=\left[\begin{array}{cccc}
1 & \tilde{a}_{12}^{(h)} & \ldots & \tilde{a}_{1 n}^{(h)} \\
\tilde{a}_{21}^{(h)} & 1 & \ldots & \tilde{a}_{2 n}^{(h)} \\
\ldots & \ldots & \ldots & \ldots \\
\tilde{a}_{n 1}^{(h)} & \tilde{a}_{n 2}^{(h)} & \ldots & 1
\end{array}\right] ; h=1,2, \ldots, q
$$

Where $\tilde{a}_{i j}^{(h)}$ is the value of the pairwise comparison between factors $i$ and $j$ by expert $h$. In fact, $\tilde{a}_{i j}^{(h)}=\left(l_{i j}^{(h)}, m_{i j}^{(h)}, u_{i j}^{(h)}\right)$.

Step 3. This step calculates the mean of all experts' opinions on the comparison value between two factors $i$ and $j$. For example, if we compare factor 2 with factor 5 based on 10 survey responses from 10 experts, we will need to consider the 10 responses (scores with respect to linguistic scales and triangular fuzzy numbers) about the relation between factors 2 and 5 . The mean of these 10 scores would be a fair final score to represent the relation between factors 2 and 5 . For this purpose, the geometric mean approach is applied. By using Eq. (2), the geometric mean of fuzzy comparison value is calculated between factor $i$ and factor $j$ as $\tilde{d}_{i j}$ :

$$
\tilde{d}_{i j}=\left(\tilde{a}_{i j}^{(1)} \otimes \tilde{a}_{i j}^{(2)} \ldots \otimes \tilde{a}_{i j}^{(q)}\right) / q
$$

Step 4. This step assigns fuzzy weights to all the criteria. The values of fuzzy extent are first computed for each dimension based on the extent analysis approach (Chang, 1992). The values of fuzzy synthetic extent (fuzzy weights) with respect to the fuzzy extent values of dimensions for each criterion are then calculated by Eq. (3):

$$
\widetilde{w}_{i}=\widetilde{w}_{j}=\widetilde{M}_{i} \otimes\left(\widetilde{M}_{1} \otimes \widetilde{M}_{2} \ldots \otimes \widetilde{M}_{n}\right)^{-1}
$$

Where $\widetilde{M}_{i}=\sum_{j=1}^{n} \tilde{d}_{i j}$.

\subsection{MOORA-G}

Brauers and Zavadskas (2006) developed the MOORA method as one of the latest MADM methods and applied it in a case study on privatization in a transition economy, to demonstrate the applicability of the MOORA method. The MOORA method involves both reference point approach and ratio system approach to rank the alternatives. The reference point method, a quasisatisficing behavior approach for multiple criteria optimization proposed by Wierzbicki (1984), applies a maximal objective reference point to validate the consequences and keep them under control (Kalirasu et al., 2017). The ratio system takes the sum of responses of alternatives as the denominator, which consequently limits between zero and one (Sarkar et al., 2015). In this study, we incorporate gray numbers into the MOORA method and hence the MOORA-G approach. We start with the gray numbers' operations, and then provide the steps of the MOORA-G approach.

Suppose $G_{1}=\left[\underline{G}_{1}, \bar{G}_{1}\right]$ and $G_{2}=\left[\underline{G}_{2}, \bar{G}_{2}\right]$ as two gray numbers, the main gray operations are defined as follows according to Abdulshahed et al. (2017):

$$
G_{1}+G_{2}=\left[\underline{G}_{1}+\underline{G}_{2}, \bar{G}_{1}+\bar{G}_{2}\right]
$$




$$
\begin{aligned}
& G_{1}-G_{2}=\left[\underline{G}_{1}-\bar{G}_{2}, \bar{G}_{1}-\underline{G}_{2}\right], \\
& -G_{1}=\left[-\bar{G}_{1},-\underline{G}_{1}\right], \\
& \frac{1}{G_{1}}=\left[\frac{1}{\bar{G}_{1}}, \frac{1}{\underline{G}_{1}}\right], \\
& G_{1} \times G_{2}=\left[\underline{G}_{1} \times \underline{G}_{2}, \bar{G}_{1} \times \bar{G}_{2}\right], \\
& \frac{G_{1}}{G_{2}}=\left[\min \left\{\frac{\underline{G}_{1}}{\underline{G}_{2}}, \frac{\underline{G}_{1}}{\bar{G}_{2}}, \frac{\bar{G}_{1}}{\underline{G}_{2}}, \frac{\bar{G}_{1}}{\bar{G}_{2}}\right\}, \max \left\{\frac{\underline{G}_{1}}{\underline{G}_{2}}, \frac{\underline{G}_{1}}{\bar{G}_{2}}, \frac{\bar{G}_{1}}{\underline{G}_{2}}, \frac{\bar{G}_{1}}{\bar{G}_{2}}\right\},\right. \\
& k \times G_{1}=\left[k \underline{G}_{1}, k \bar{G}_{1}\right], k \in R^{+}
\end{aligned}
$$

The proposed MOORA-G works as follows:

Step 1. Consider the significant factors which are related to the alternatives. This step adopts the weights calculated by the fuzzy AHP for all the criteria.

Step 2. Organize the initial gray decision matrix as $X$ in Eq. (4).

$$
X=\left[\begin{array}{cccc}
{\left[x_{11} ; u_{11}\right]} & {\left[x_{12} ; u_{12}\right]} & \ldots & {\left[x_{1 n} ; u_{1 n}\right]} \\
{\left[x_{21} ; u_{21}\right]} & {\left[x_{22} ; u_{22}\right]} & \ldots & {\left[x_{2 n} ; u_{2 n}\right]} \\
\ldots & \ldots & \ldots & \ldots \\
{\left[x_{m 1} ; u_{m 1}\right]} & {\left[x_{m 2} ; u_{m 2}\right]} & \ldots & {\left[x_{m n} ; u_{m n}\right]}
\end{array}\right] ; k=1,2, \ldots, m ; j=1,2, \ldots, n
$$

where $n$ is the number of factors and $m$ is the number of alternatives (3PRLPs) which are considered for evaluation. In other words, the alternatives are arranged in matrix vertically and the criteria are set horizontally. Each element $\left[x_{k j} ; u_{k j}\right]$ in $X$ is defined by $x_{k j}$ as the lower limit and $u_{k j}$ as the upper limit and demonstrates the importance of the alternative $k$ for the factor $j$.

Step 3. Using Eqs. (5) and (6), the initial gray decision matrix is normalized and introduced as the normalized decision-making matrix $\bar{X}$ in Eq. (7). Eqs. (5) and (6) normalize the matrix elements into dimensionless numbers between zero and one (Akkaya et al., 2015). By doing so, the numbers become comparable each other which leads to simplified inter-factor comparisons.

$$
\begin{aligned}
& {[\bar{x}]_{m \times n}=\frac{2 x_{k j}}{\left(\sum_{k=1}^{m} x_{k j}\right)\left(\sum_{k=1}^{m} u_{k j}\right)}} \\
& {[\bar{u}]_{m \times n}=\frac{2 u_{k j}}{\left(\sum_{k=1}^{m} x_{k j}\right)\left(\sum_{k=1}^{m} u_{k j}\right)}} \\
& \bar{X}=\left[\begin{array}{cccc}
{\left[\bar{x}_{11} ; \bar{u}_{11}\right]} & {\left[\bar{x}_{12} ; \bar{u}_{12}\right]} & \ldots & {\left[\bar{x}_{1 n} ; \bar{u}_{1 n}\right]} \\
{\left[\bar{x}_{21} ; \bar{u}_{21}\right]} & {\left[\bar{x}_{22} ; \bar{u}_{22}\right]} & \ldots & {\left[\bar{x}_{1 n} ; \bar{u}_{1 n}\right]} \\
\ldots & \ldots & \ldots & \ldots \\
{\left[\bar{x}_{m 1} ; \bar{u}_{m 1}\right]} & {\left[\bar{x}_{m 2} ; \bar{u}_{m 2}\right]} & \ldots & {\left[\bar{x}_{m n} ; \bar{u}_{m n}\right]}
\end{array}\right] ; k=1,2, \ldots, m ; j=1,2, \ldots, n
\end{aligned}
$$

Step 4. Computed weights for each factor by fuzzy AHP method are multiplied in normalized decision-making matrix $\bar{X}$ to calculate the weighted normalized decision matrix $\hat{X}$. The weights are multiplied by Eqs. (8) and (9). 


$$
\hat{x}_{k j}=\bar{x}_{k j} \times w_{j}
$$

$\hat{u}_{k j}=\bar{u}_{k j} \times w_{j}$

Where $k=1,2, \ldots, m ; j=1,2, \ldots, n$ and $w_{j}$ is the weight of the $j$ th factor considered by the fuzzy AHP.

Step 5. Eventually, the weighted normalized decision-making matrix $\hat{X}$ is structured as the final decision-making matrix as Eq. (10).

$$
\hat{X}=\left[\begin{array}{cccc}
{\left[\hat{x}_{11} ; \hat{u}_{11}\right]} & {\left[\hat{x}_{12} ; \hat{u}_{12}\right]} & \ldots & {\left[\hat{x}_{1 n} ; \hat{u}_{1 n}\right]} \\
{\left[\hat{x}_{21} ; \hat{u}_{21}\right]} & {\left[\hat{x}_{22} ; \hat{u}_{22}\right]} & \ldots & {\left[\hat{x}_{1 n} ; \hat{u}_{1 n}\right]} \\
\ldots & \ldots & \ldots & \ldots \\
{\left[\hat{x}_{m 1} ; \hat{u}_{m 1}\right]} & {\left[\hat{x}_{m 2} ; \hat{u}_{m 2}\right]} & \ldots & {\left[\hat{x}_{m n} ; \hat{u}_{m n}\right]}
\end{array}\right] ; k=1,2, \ldots, m ; j=1,2, \ldots, n
$$

Step 6. The normalized performance values are computed by deducing the total downside criteria or cost criteria (if the desirable value of a factor is maximum) from the total of upside criteria or benefit criteria (if the desirable value of a factor is minimum) (Baležentis et al., 2012) by Eq. (11).

$$
\hat{y}_{k}=\sum_{j=1}^{g} \hat{v}_{k j}-\sum_{j=g+1}^{n} \hat{v}_{k j}
$$

Where $\sum_{j=1}^{g} \hat{v}_{k j}$ is the total of upside factors for $(1, \ldots, g)$ and $\sum_{j=g+1}^{n} \hat{v}_{k j}$ is the total of downside factors for $(g+1, \ldots, n)$. Here, $g$ is number of benefit factors to be determined and $(n-$ $g$ ) is the number of cost factors to be determined.

Step 7. To achieve the Best Non-Gray Performance (BNGP), the first gray numbers (the gray normalized performance values) should be turned into the crisp numbers. These computations are carried out by Eq. (12).

$$
B N G P_{k}\left(y_{k}\right)=\frac{\hat{x}_{k j}+\hat{u}_{k j}}{2}
$$

Finally, based on the value of $B N G P_{k}\left(y_{k}\right)$, the alternative with the largest value of $B N G P_{k}\left(y_{k}\right)$ will be ranked first and the other alternatives are ranked with this rule.

\section{Case Study and Results}

In this section, we use a case study to demonstrate the applicability of the proposed hybrid approach. We describe how the data was collected from case study experts, present the results based on the proposed hybrid approach, and finally provide a conclusion to the case and discuss the business implications.

\subsection{Case Study}

The case study is with Kerman Khodro Powertrain Co. (KPT Co.). KPT Co. was established in 1999 as a private joint-stock in the special economic zone Bam in Kerman province, Iran. It 
assembles engine, gearbox, and axle, and produces main parts of passenger car powertrain such as cylinder blocks, cylinder heads, gears, shafts, gearbox housings, connecting rods and pistons. KPT Co. launched its first assembly line for engines, gearboxes, and axles in 2001; the piston casting and machining lines in 2009; and the production lines of gears, shafts, and housings in 2011. Table 5 reports its annual assembling and manufacturing capacities.

Table 5. The annual assembling and manufacturing capacities of KPT Co.

\begin{tabular}{ll|ll}
\hline Assembling Capacity & & Manufacturing Capacity & \\
\hline Engine sets & 200,000 & Transmission Sets Including & 100,000 \\
Gearbox sets & 300,000 & Housings, Gears, and Shafts & Cylinder Heads \\
\hline Axle sets & 200,000 & Cylinder Blocks & 120,000 \\
\hline $\begin{array}{l}\text { Steering Boxes, Suspensions and } \\
\text { Brakes sets }\end{array}$ & $1,000,000$ & Connecting Rods & 200,000 \\
\hline & Pistons & 400,000 \\
\hline
\end{tabular}

KPT Co. as an Original Equipment Manufacturer supplier has produced engine, gearbox and axle assemblies for the following car manufacturers: Daewoo, Volkswagen, Hyundai, MVM/Chery, Lifan and SAIPA (as the second car producer of Iran). KPT Co. has cooperated with reputable companies from Germany, Australia, Italy, South Korea, Slovenia, and China for technology transfer in different fields of manufacturing and production, packaging and homologation. It should be mentioned that DQS issued ISO 9001-2000 and ISO-TS16949 certificates to KPT Co. in 2004 and 2005. In 2016, IMQ awarded ISO-TS 16949:2008 certificate to all KPT Co. manufacturing and assembling lines.

KPT Co. is capable of providing relevant services in modifying new platforms, homologation, and packaging and obtaining the relevant certificates. Moreover, it has produced engines that are among the lowest-fuel-consuming ones in Iran conforming to the latest national and international pollution and environment regulations. For this reason, head managers of the company have decided to run reverse logistics activities to not only reduce cost but also to lift the company's sustainability image. However, evaluation of several scenarios led to the decision to outsource the reverse logistics activities to 3PRLPs, and hence the need to evaluate them accordingly.

\subsection{Data Collection}

In this research, 12 experts have helped to complete survey questionnaires to rank nine 3PRLPs who all have more than eight years of experience in the car parts manufacturing industry. The process of filling out the questionnaires with the 12 industry experts comprised two steps. First, appointments were scheduled with the experts and the questionnaires were distributed to them. Elaboration was provided on how they should fill out the questionnaires to reduce vagueness/misinterpretation. Secondly, initial evaluation was carried out and doubts on experts' answers were clarified. The final questionnaires were then used to complete the initial fuzzy decision matrix. In this way, the ideas of the experts were turned to triangular fuzzy numbers to obtain more viable results and weights, which were then normalized, weighted and completed the weighted normalized fuzzy decision matrix to derive the ranking of 3PRLPs. As discussed in the 
literature review section, the considered criteria set in Table 3 was the results from reviewing the literature and discussion amongst the authors and the experts.

\subsection{Fuzzy AHP Results}

This section reports the results of the fuzzy AHP method, which calculates and allocates weights for each criterion in each dimension. Since some of the criteria are qualitative, they may impact on each other. Therefore, fuzzy AHP is supposed to cover the relation and impact of criteria on each other and deal with the uncertainty of qualitative criteria. Table 6 provides the weights for each dimension and then the weights of sub-criteria are calculated in their dimensions separately, which are presented in Tables 7-10 for economic, environmental, social, and risk and safety dimensions, respectively. All the tables (matrices) in this section are derived from the questionnaires filled out by the 12 experts, using the fuzzy membership functions in Table 4 .

Table 6 provides the calculated weights for each dimension. It can be seen that the social dimension obtains the highest weight, followed by the economic dimension. Environmental dimension ranks third, while risk and safety ranks last. The social dimension achieves the highest weight is demonstrative of the experts' opinions on issues such as human right, working hours, health and so on. They have a considerable position in relation to the company strategies (in this case reverse logistics). The economic dimension ranks second, as one of the basic goals of 3PRLP operations is to bring profit and competitive advantage to companies.

Table 7 presents the computed criteria's weights within the economic dimension. A glance at Table 7 reveals that the greatest weights among the economic criteria are the lead time, quality and cost. Table 8 displays weights about the environmental criteria. It is obvious that the environmental criteria receive similar weights, in such a way that it is so hard to determine which one is the highest or lowest. This trend can be similarly observed for social criteria in Table 9. Apart from voice of customer, which has the lowest weight, the other criteria receive roughly equal weights to each other. It is interesting to see that social criteria achieve the highest weights against criteria in other dimensions. In Table 10 which is related to the weights of risk and safety criteria, financial risk gains the maximum weight which denotes that this criterion is more significant than the other criteria in this dimension. This shows a clear link to the ranking of economic dimension. Overall, the weights assigned to all the criteria show that they are directly influenced by the corresponding dimensional weights. These results in a way prove the accuracy and validate the proposed fuzzy AHP, as the dimensional weights are multiplied to their criteria during the solving process of fuzzy AHP. 
Table 6. Pairwise comparisons of dimensions of criteria for 3PRLP selection.

\begin{tabular}{|c|c|c|c|c|c|c|c|c|c|c|c|c|c|c|c|}
\hline \multirow{2}{*}{$\begin{array}{c}\text { Dimensions } \\
\text { Economic }\end{array}$} & \multicolumn{3}{|c|}{ Economic } & \multicolumn{3}{|c|}{ Environmental } & \multicolumn{3}{|c|}{ Social } & \multicolumn{3}{|c|}{ Risk and Safety } & \multicolumn{3}{|c|}{$\begin{array}{c}\text { Dimension Fuzzy } \\
\text { Weight }\end{array}$} \\
\hline & 1 & 1 & 1 & .981 & 3.793 & 5.954 & 3.365 & 5.099 & 7.344 & 2.218 & 3.411 & 5.702 & 0.131 & 0.274 & 0.52 \\
\hline Environmental & 1.721 & 2.484 & 4.849 & 1 & 1 & 1 & 2.82 & 4.62 & 6.848 & 2.446 & 3.512 & 5.784 & 0.124 & 0.242 & 0.488 \\
\hline Social & 2.838 & 4.159 & 6.472 & 3.317 & 5.063 & 7.192 & 1 & 1 & 1 & 2.94 & 3.983 & 6.159 & 0.154 & 0.291 & 0.539 \\
\hline Risk and Safety & 2.266 & 2.94 & 4.845 & 1.582 & 2.232 & 4.094 & 1.505 & 2.536 & 4.818 & 1 & 1 & 1 & 0.102 & 0.194 & 0.41 \\
\hline
\end{tabular}

Table 7. Pairwise comparisons of criteria of economic dimension for 3PRLP selection.

\begin{tabular}{|c|c|c|c|c|c|c|c|c|c|c|c|c|c|c|c|c|c|c|}
\hline \multirow{2}{*}{$\begin{array}{l}\text { Economic Criteria } \\
\text { Quality }\end{array}$} & \multicolumn{3}{|c|}{ Quality } & \multicolumn{3}{|c|}{ Cost } & \multicolumn{3}{|c|}{ Lead Time } & \multicolumn{3}{|c|}{ Delivery } & \multicolumn{3}{|c|}{ Services } & \multicolumn{3}{|c|}{ Capability of R \& D } \\
\hline & .000 & 1.000 & 1.000 & .981 & 3.793 & 5.954 & 3.365 & 5.099 & 7.344 & 2.218 & 3.411 & 5.702 & 2.346 & 3.898 & 5.950 & 2.157 & 3.661 & 5.950 \\
\hline Cost & 1.721 & 2.484 & 4.849 & 1.000 & 1.000 & 1.000 & 2.820 & 4.620 & 6.848 & 2.446 & 3.512 & 5.784 & 3.869 & 5.956 & 7.612 & 2.112 & 3.362 & 5.662 \\
\hline Lead Time & 2.838 & 4.159 & 6.472 & 3.317 & 5.063 & 7.192 & 1.000 & 1.000 & 1.000 & 2.940 & 3.983 & 6.159 & 3.133 & 5.357 & 7.197 & 2.608 & 4.489 & 6.521 \\
\hline Delivery & 2.266 & 2.940 & 4.845 & 1.582 & 2.232 & 4.094 & 1.505 & 2.536 & 4.818 & 1.000 & 1.000 & 1.000 & 1.289 & 1.649 & 3.842 & 1.770 & 2.314 & 4.646 \\
\hline Services & 2.054 & 3.608 & 5.908 & 2.329 & 3.793 & 5.992 & 1.685 & 3.002 & 5.242 & 2.397 & 3.359 & 5.541 & 1.000 & 1.000 & 1.000 & 1.505 & 2.112 & 4.424 \\
\hline Capability Of R \& D & 1.685 & 3.002 & 5.242 & 1.433 & 1.899 & 4.210 & 1.770 & 2.314 & 4.646 & 1.516 & 2.607 & 4.783 & 1.096 & 1.981 & 4.156 & 1.000 & 1.000 & 1.000 \\
\hline Local Fuzzy Weight & .082 & 0.192 & 0.401 & 0.086 & 0.187 & 0.397 & 0.099 & 0.218 & 0.431 & 0.061 & 0.122 & 0.305 & 0.070 & 0.158 & 0.359 & 0.055 & 0.124 & 0.314 \\
\hline Final Weight & 0.011 & 0.052 & 0.209 & 0.011 & 0.051 & 0.207 & 0.013 & 0.060 & 0.224 & 0.008 & $\mathbf{0 . 0 3 3}$ & 0.159 & 0.009 & 0.043 & 0.187 & 0.007 & 0.034 & 0.164 \\
\hline
\end{tabular}

Table 8. Pairwise comparisons of criteria of environmental dimension for 3PRLP selection.

\begin{tabular}{|c|c|c|c|c|c|c|c|c|c|c|c|c|c|c|c|c|c|c|c|c|c|c|c|c|}
\hline Environmental & \multicolumn{3}{|c|}{ Green Design } & \multicolumn{3}{|c|}{ Reuse } & \multicolumn{3}{|c|}{ Remanufacture } & \multicolumn{3}{|c|}{ Refurbish } & \multicolumn{3}{|c|}{ Recycle } & \multicolumn{3}{|c|}{ Disposal } & \multicolumn{3}{|c|}{ Air Emissions } & \multicolumn{3}{|c|}{ Green Packaging } \\
\hline Green Design & 1.000 & 1.000 & 1.000 & 2.590 & 3.986 & 6.293 & 2.011 & .759 & 5.163 & .799 & 4.302 & 6.381 & 2.940 & 4.783 & 6.706 & 2.780 & 3.820 & 6.159 & 2.554 & 3.762 & 5.946 & 3.155 & 5.505 & 7.146 \\
\hline Reuse & 2.536 & 3.340 & 5.739 & 1.000 & 1.000 & 1.000 & .218 & 3.411 & 5.702 & .608 & 4.096 & 6.249 & 1.982 & 2.739 & 5.056 & 1.733 & 2.126 & 4.421 & 2.218 & 3.411 & 5.702 & 3.608 & 5.391 & 7.192 \\
\hline Remanufacture & 3.411 & 5.666 & 7.504 & 3.765 & 5.544 & 7.344 & 1.000 & 1.000 & 1.000 & 4.273 & 5.541 & 7.187 & 2.250 & 3.288 & 5.387 & 1.538 & 2.625 & 4.885 & 2.840 & 4.333 & 6.516 & 1.345 & 1.696 & 3.923 \\
\hline Refurbish & 3.222 & 4.555 & 6.609 & 2.314 & 3.844 & 6.076 & 2.250 & 3.135 & 5.580 & 1.000 & 1.000 & 1.000 & 1.874 & 2.627 & 5.056 & 2.266 & 4.646 & 6.569 & 3.004 & 3.762 & 5.984 & 2.983 & 4.818 & 6.848 \\
\hline Recycle & 1.783 & 2.857 & 5.024 & 2.024 & 3.269 & 5.544 & 2.573 & 4.427 & 6.659 & 3.533 & 4.518 & 6.558 & 1.000 & 1.000 & 1.000 & 3.710 & 6.033 & 7.504 & 2.520 & 3.710 & 6.072 & 1.886 & 3.113 & 5.430 \\
\hline Disposal & 2.741 & 3.951 & 6.072 & 1.847 & 2.608 & 4.951 & 3.201 & 4.617 & 6.701 & 2.380 & 3.269 & 5.580 & 2.204 & 2.879 & 5.310 & 1.000 & 1.000 & 1.000 & 1.253 & 2.126 & 4.365 & 1.860 & 2.446 & 4.711 \\
\hline Air Emissions & 1.516 & 2.379 & 4.584 & 2.266 & 3.869 & 6.033 & 2.647 & 4.955 & 6.948 & 2.024 & 2.722 & 5.092 & 2.940 & 4.365 & 6.426 & 2.448 & 4.009 & 6.076 & 1.000 & 1.000 & 1.000 & 2.448 & 4.393 & 6.340 \\
\hline $\begin{array}{l}\text { Management For } \\
\text { Hazardous Substances }\end{array}$ & 2.204 & 3.457 & 5.782 & 2.554 & 4.123 & 6.205 & 3.292 & 4.714 & 6.701 & 2.840 & 5.203 & 7.095 & 2.840 & 3.954 & 6.245 & 2.363 & 3.820 & 6.119 & 3.068 & 4.489 & 6.562 & 1.000 & 1.000 & 1.000 \\
\hline Local Fuzzy Weight & 0.062 & 0.134 & 0.282 & 0.056 & 0.115 & 0.259 & 0.060 & 0.126 & 0.271 & 0.059 & 0.128 & 0.275 & 0.058 & 0.129 & 0.275 & 0.051 & 0.104 & 0.246 & 0.054 & 0.124 & 0.268 & 0.063 & 0.139 & 0.287 \\
\hline Final Weight & 0.008 & 0.033 & 0.137 & 0.007 & 0.028 & 0.126 & 0.007 & 0.031 & 0.132 & 0.007 & 0.031 & 0.134 & 0.007 & 0.031 & 0.134 & 0.006 & 0.025 & 0.120 & 0.007 & 0.030 & 0.130 & 0.008 & 0.034 & 0.140 \\
\hline
\end{tabular}


Table 9. Pairwise comparisons of criteria of social dimension for 3PRLP selection.

\begin{tabular}{|c|c|c|c|c|c|c|c|c|c|c|c|c|c|c|c|}
\hline Social Criteria & \multicolumn{3}{|c|}{ Health } & \multicolumn{3}{|c|}{$\begin{array}{c}\text { Flexible Working } \\
\text { Arrangements }\end{array}$} & \multicolumn{3}{|c|}{ Voice Of Customer } & \multicolumn{3}{|c|}{$\begin{array}{c}\text { Respect For The } \\
\text { Policy }\end{array}$} & \multicolumn{3}{|c|}{ Reputation } \\
\hline Health & 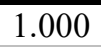 & 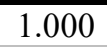 & 1.000 & 4.040 & 5.823 & 7.499 & 250 & 3.603 & 5.622 & 112 & 3.362 & 5.662 & 3.457 & 4.783 & 6.749 \\
\hline $\begin{array}{l}\text { Flexible V } \\
\text { Arrangem }\end{array}$ & 2.554 & 4.123 & 6.205 & 1.000 & 1.000 & 1.000 & 2.380 & 4.302 & 6.340 & 3.224 & 5.200 & 6.943 & 2.234 & 3.199 & 5.426 \\
\hline Voice Of Customer & 759 & 3.383 & 5.586 & 2.204 & 4.550 & 6.569 & 1.000 & 1.000 & 1.000 & 2.172 & 3.433 & 5.662 & 2.859 & 4.684 & 6.706 \\
\hline Respect For The Policy & 2.172 & 3.762 & 5.908 & 4.040 & 6.381 & 7.825 & 2.448 & 3.658 & & 1.000 & 1.000 & 1.000 & 2.281 & 4.183 & 6.209 \\
\hline Reputation & 2.665 & 3.531 & 5.819 & 1.886 & 3.113 & 5.430 & 3.362 & 5.133 & 7.043 & 3.340 & 4.748 & 6.843 & 1.000 & 1.000 & 1.000 \\
\hline Local Fuzzy & .107 & 0.218 & 0.409 & 0.098 & 0.212 & 0.402 & 0.087 & 0.205 & 0.397 & 0.100 & 0.222 & 0.412 & 0.103 & 0.208 & 0.404 \\
\hline Final Weight & 0.016 & 0.063 & 0.220 & 0.015 & 0.062 & 0.217 & 0.013 & 0.059 & 0.214 & 0.015 & 0.064 & 0.222 & 0.016 & 0.060 & 0.218 \\
\hline
\end{tabular}

Table 10. Pairwise comparisons of criteria of risk and safety dimension for 3PRLP selection.

\begin{tabular}{|c|c|c|c|c|c|c|c|c|c|c|c|c|}
\hline Risk and safety criteria & \multicolumn{3}{|c|}{ Operational Risk } & \multicolumn{3}{|c|}{ Organizational Risk } & \multicolumn{3}{|c|}{ Financial Risk } & \multicolumn{3}{|c|}{ Safety } \\
\hline Operational Risk & 1.000 & 1.000 & 1.000 & 2.590 & 3.986 & 6.293 & 2.011 & 2.759 & 5.163 & 2.799 & 4.302 & 6.381 \\
\hline Organizational Risk & 2.536 & 3.340 & 5.739 & 1.000 & 1.000 & 1.000 & 2.218 & 3.411 & 5.702 & 2.608 & 4.096 & 6.249 \\
\hline Financial Risk & 3.411 & 5.666 & 7.504 & 3.765 & 5.544 & 7.344 & 1.000 & 1.000 & 1.000 & 4.273 & 5.541 & 7.187 \\
\hline Safety & 3.222 & 4.555 & 6.609 & 2.314 & 3.844 & 6.076 & 2.250 & 3.135 & 5.580 & 1.000 & 1.000 & 1.000 \\
\hline Local Fuzzy Weight & 0.123 & 0.226 & 0.438 & 0.123 & 0.226 & 0.437 & 0.171 & 0.313 & 0.515 & 0.127 & 0.235 & 0.447 \\
\hline Final Weight & 0.013 & 0.044 & 0.180 & 0.013 & 0.044 & 0.179 & 0.017 & 0.061 & 0.211 & 0.013 & 0.046 & 0.183 \\
\hline
\end{tabular}

\subsection{MOORA-G results}

This section presents the results obtained by MOORA-G. Table 11 displays the initial gray decision matrix, which is first constructed based on the questionnaire survey results from the 12 experts and the linguistic scales presented in Table 4 . The initial gray decision matrix is subsequently normalized to obtain the normalized gray decision matrix (Table 12). Therefore, the weighted normalized gray decision matrix (the value matrix) for evaluation and ranking the alternatives (3PRLPs) is computed by applying achieved weights from fuzzy AHP to normalized gray decision matrix (Table 12) which is provided in Table 13 and the final computations for alternatives ranking are calculated according to Table 13. 
Table 11. Initial gray decision matrix with evaluation 3PRLPs (Alternatives) and criteria.

\begin{tabular}{|c|c|c|c|c|c|c|c|c|c|c|c|c|c|c|c|c|}
\hline \multirow{2}{*}{$\begin{array}{c}\text { Alternatives } \\
\text { 3PRLP } 1\end{array}$} & \multicolumn{2}{|c|}{ Quality } & \multicolumn{2}{|c|}{ Cost } & \multicolumn{2}{|c|}{ Lead Time } & \multicolumn{2}{|c|}{ Delivery } & \multicolumn{2}{|c|}{ Services } & \multicolumn{2}{|c|}{$\begin{array}{c}\text { Capability of R } \\
\text { \& D } \\
\end{array}$} & \multicolumn{2}{|c|}{ Green Design } & \multicolumn{2}{|c|}{ Reuse } \\
\hline & 3.50 & 4.83 & 4.42 & 5.92 & 2.75 & 4.25 & 4.17 & 5.83 & 3.67 & 5.25 & 2.92 & 4.42 & 2.50 & 3.83 & 4.25 & 5.83 \\
\hline 3PRLP 2 & 3.75 & 5.25 & 3.17 & 4.75 & 1.92 & 3.33 & 3.08 & 4.67 & 3.58 & 4.75 & 4.17 & 5.50 & 4.25 & 5.83 & 4.75 & 6.00 \\
\hline 3PRLP 3 & 3.92 & 5.25 & 3.83 & 5.33 & 4.67 & 6.25 & 2.92 & 4.17 & 4.00 & 5.17 & 4.08 & 5.33 & 2.58 & 3.83 & 2.25 & 3.92 \\
\hline 3PRLP 4 & 4.33 & 5.83 & 3.00 & 4.33 & 2.58 & 4.00 & 4.08 & 5.08 & 3.25 & 4.58 & 2.83 & 4.17 & 3.33 & 4.75 & 2.75 & 4.08 \\
\hline 3PRLP 5 & 4.33 & 5.92 & 3.17 & 4.33 & 4.00 & 5.17 & 4.92 & 6.67 & 4.17 & 5.58 & 4.67 & 6.08 & 2.75 & 4.33 & 2.83 & 4.25 \\
\hline 3PRLP 6 & 6.67 & 8.00 & 4.08 & 5.67 & 4.42 & 6.17 & 4.17 & 5.58 & 4.17 & 5.83 & 4.00 & 5.17 & 4.83 & 6.00 & 3.33 & 4.67 \\
\hline 3PRLP 7 & 4.17 & 5.83 & 3.17 & 4.67 & 3.92 & 5.25 & 4.17 & 5.33 & 4.42 & 5.58 & 4.67 & 6.25 & 5.00 & 6.25 & 4.17 & 5.25 \\
\hline 3PRLP 8 & 5.33 & 6.50 & 3.50 & 5.17 & 3.42 & 5.08 & 4.00 & 5.58 & 4.00 & 5.33 & 3.83 & 5.50 & 5.08 & 6.75 & 4.00 & 5.67 \\
\hline 3PRLP 9 & 4.33 & 5.75 & 3.75 & 5.08 & 6.00 & 7.00 & 5.33 & 6.50 & 4.00 & 5.58 & 4.83 & 6.42 & 3.25 & 4.75 & 4.08 & 5.83 \\
\hline Alternatives & \multicolumn{2}{|c|}{ Remanufacture } & \multicolumn{2}{|c|}{ Refurbish } & \multicolumn{2}{|c|}{ Recycle } & \multicolumn{2}{|c|}{ Disposal } & \multicolumn{2}{|c|}{ Air Emissions } & \multicolumn{2}{|c|}{$\begin{array}{c}\text { Green } \\
\text { Packaging }\end{array}$} & \multicolumn{2}{|c|}{ Health } & \multicolumn{2}{|c|}{$\begin{array}{c}\text { Flexible Working } \\
\text { Arrangements }\end{array}$} \\
\hline 3PRLP 1 & 3.67 & 5.00 & 3.50 & 4.92 & 3.83 & 5.33 & 3.67 & 5.33 & 4.58 & 6.33 & 5.17 & 6.42 & 3.58 & 4.92 & 2.33 & 3.58 \\
\hline 3PRLP 2 & 4.58 & 6.00 & 4.25 & 5.50 & 4.08 & 5.67 & 2.75 & 4.33 & 3.75 & 4.92 & 3.00 & 4.25 & 4.00 & 5.42 & 2.75 & 4.25 \\
\hline 3PRLP 3 & 4.58 & 5.75 & 3.58 & 5.25 & 3.83 & 5.08 & 4.50 & 6.08 & 4.08 & 5.42 & 4.00 & 5.50 & 4.58 & 6.17 & 4.67 & 6.17 \\
\hline 3PRLP 4 & 3.50 & 4.83 & 4.50 & 6.00 & 4.33 & 5.58 & 3.17 & 4.33 & 4.08 & 5.67 & 3.42 & 4.67 & 5.25 & 6.67 & 2.33 & 3.50 \\
\hline 3PRLP 5 & 3.17 & 4.67 & 4.00 & 5.17 & 3.92 & 5.33 & 3.92 & 5.50 & 4.58 & 6.00 & 3.75 & 5.25 & 4.00 & 5.17 & 3.33 & 4.75 \\
\hline 3PRLP 6 & 3.83 & 5.33 & 3.75 & 5.25 & 4.50 & 6.42 & 4.25 & 5.58 & 4.33 & 5.75 & 4.17 & 6.00 & 4.58 & 6.25 & 3.75 & 5.25 \\
\hline 3PRLP 7 & 3.42 & 4.58 & 4.92 & 6.42 & 3.42 & 4.58 & 4.25 & 5.50 & 4.33 & 6.00 & 2.42 & 4.00 & 3.50 & 5.08 & 5.25 & 6.83 \\
\hline 3PRLP 8 & 3.58 & 4.92 & 3.83 & 5.17 & 3.25 & 4.92 & 5.50 & 6.50 & 4.42 & 5.83 & 5.58 & 6.92 & 4.67 & 6.08 & 3.83 & 5.50 \\
\hline 3PRLP 9 & 3.83 & 5.17 & 4.42 & 5.58 & 3.75 & 5.00 & 4.58 & 5.92 & 5.17 & 6.83 & 3.42 & 4.92 & 4.00 & 5.50 & 3.75 & 5.08 \\
\hline Alternatives & \multicolumn{2}{|c|}{$\begin{array}{l}\text { Voice Of } \\
\text { Customer }\end{array}$} & \multicolumn{3}{|c|}{$\begin{array}{c}\begin{array}{c}\text { Respect For The } \\
\text { Policy }\end{array} \\
\end{array}$} & \multicolumn{2}{|c|}{ Reputation } & \multicolumn{2}{|c|}{ Operational Risk } & \multicolumn{2}{|c|}{$\begin{array}{c}\text { Organizational } \\
\text { Risk }\end{array}$} & \multicolumn{3}{|c|}{ Financial Risk } & \multicolumn{2}{|c|}{ Safety } \\
\hline 3PRLP 1 & 4.42 & 5.83 & 3.3 & & & 4.50 & 5.83 & 4.75 & 5.92 & 3.92 & 6.00 & 4.0 & & 08 & 5.33 & 6.42 \\
\hline 3PRLP 2 & 3.67 & 5.17 & 4.4 & & & 5.00 & 6.67 & 4.75 & 5.92 & 2.75 & 4.17 & 3.0 & & 58 & 3.42 & 5.00 \\
\hline 3PRLP 3 & 2.75 & 4.00 & 4.2 & & & 4.75 & 6.50 & 2.25 & 3.58 & 2.83 & 4.17 & 4.8 & & 67 & 4.92 & 6.58 \\
\hline 3PRLP 4 & 3.75 & 5.33 & 5.6 & & & 5.50 & 7.25 & 4.17 & 5.92 & 4.25 & 5.75 & 4. & & 92 & 4.83 & 6.08 \\
\hline 3PRLP 5 & 4.00 & 5.08 & 3.2 & & & 3.33 & 4.75 & 5.00 & 6.50 & 3.08 & 4.58 & 3.5 & & 17 & 4.08 & 5.50 \\
\hline 3PRLP 6 & 3.75 & 5.25 & 2.6 & & & 3.33 & 4.50 & 4.75 & 6.25 & 4.17 & 5.92 & 4.6 & & 17 & 1.83 & 3.17 \\
\hline 3PRLP 7 & 3.83 & 5.00 & 4.1 & & & 4.83 & 5.92 & 3.67 & 4.92 & 3.42 & 4.67 & 2.9 & & 50 & 3.08 & 4.33 \\
\hline 3PRLP 8 & 3.33 & 5.00 & 2.5 & & & 2.33 & 3.67 & 3.00 & 4.42 & 5.92 & 7.25 & 5.0 & & 42 & 3.42 & 4.83 \\
\hline 3PRLP 9 & 4.08 & 5.33 & 3.1 & & & 5.42 & 7.25 & 3.50 & 4.92 & 3.83 & 5.00 & 3.2 & & 75 & 5.00 & 6.08 \\
\hline
\end{tabular}


Table 12. Normalized gray decision matrix with evaluation 3PRLPs (Alternatives) and criteria.

\begin{tabular}{|c|c|c|c|c|c|c|c|c|c|c|c|c|c|c|c|c|c|}
\hline Alternatives & \multicolumn{2}{|c|}{ Quality } & \multicolumn{2}{|c|}{ Cost } & \multicolumn{2}{|c|}{ Lead Time } & \multicolumn{2}{|c|}{ Delivery } & \multicolumn{2}{|c|}{ Services } & \multicolumn{2}{|c|}{$\begin{array}{c}\text { Capability of R } \\
\text { \& D }\end{array}$} & \multicolumn{3}{|c|}{ Green Design } & \multicolumn{2}{|c|}{ Reuse } \\
\hline 3PRLP 1 & 0.075 & 0.103 & 0.114 & 0.153 & 0.069 & 0.106 & 0.097 & 0.135 & 0.088 & 0.127 & 0.069 & 0.104 & 0.0 & & 0.096 & 0.109 & 0.150 \\
\hline 3PRLP 2 & 0.080 & 0.112 & 0.082 & 0.123 & 0.048 & 0.083 & 0.071 & 0.108 & 0.086 & 0.115 & 0.098 & 0.130 & 0.1 & & 0.146 & 0.122 & 0.154 \\
\hline 3PRLP 3 & 0.084 & 0.112 & 0.099 & 0.138 & 0.116 & 0.156 & 0.068 & 0.097 & 0.096 & 0.125 & 0.096 & 0.126 & 0.0 & & 0.096 & 0.058 & 0.101 \\
\hline 3PRLP 4 & 0.093 & 0.125 & 0.078 & 0.112 & 0.064 & 0.100 & 0.095 & 0.118 & 0.078 & 0.111 & 0.067 & 0.098 & 0.0 & & 0.119 & 0.071 & 0.105 \\
\hline 3PRLP 5 & 0.093 & 0.127 & 0.082 & 0.112 & 0.100 & 0.129 & 0.114 & 0.155 & 0.101 & 0.135 & 0.110 & 0.143 & 0.0 & & 0.108 & 0.073 & 0.109 \\
\hline 3PRLP 6 & 0.143 & 0.171 & 0.106 & 0.147 & 0.110 & 0.154 & 0.097 & 0.129 & 0.101 & 0.141 & 0.094 & 0.122 & 0.1 & & 0.150 & 0.086 & 0.120 \\
\hline 3PRLP 7 & 0.089 & 0.125 & 0.082 & 0.121 & 0.098 & 0.131 & 0.097 & 0.124 & 0.107 & 0.135 & 0.110 & 0.147 & 0.1 & & 0.156 & 0.107 & 0.135 \\
\hline 3PRLP 8 & 0.114 & 0.139 & 0.091 & 0.134 & 0.085 & 0.127 & 0.093 & 0.129 & 0.096 & 0.129 & 0.090 & 0.130 & 0.1 & & 0.169 & 0.103 & 0.145 \\
\hline 3PRLP 9 & 0.093 & 0.123 & 0.097 & 0.131 & 0.150 & 0.175 & 0.124 & 0.151 & 0.096 & 0.135 & 0.114 & 0.151 & 0.0 & & 0.119 & 0.105 & 0.150 \\
\hline Alternatives & \multicolumn{2}{|c|}{ Remanufacture } & \multicolumn{2}{|c|}{ Refurbish } & \multicolumn{2}{|c|}{ Recycle } & \multicolumn{2}{|c|}{ Disposal } & \multicolumn{2}{|c|}{ Air Emissions } & \multicolumn{2}{|c|}{$\begin{array}{c}\text { Green } \\
\text { Packaging }\end{array}$} & \multicolumn{3}{|c|}{ Health } & \multicolumn{2}{|c|}{$\begin{array}{c}\text { Flexible Working } \\
\text { Arrangements }\end{array}$} \\
\hline 3PRLP 1 & 0.091 & 0.124 & 0.081 & 0.114 & 0.093 & 0.129 & 0.086 & 0.125 & 0.100 & 0.138 & 0.125 & 0.155 & 0.1 & & 0.110 & 0.061 & 0.093 \\
\hline 3PRLP 2 & 0.114 & 0.149 & 0.099 & 0.128 & 0.099 & 0.137 & 0.064 & 0.101 & 0.081 & 0.107 & 0.072 & 0.103 & 0. & & 0.121 & 0.072 & 0.111 \\
\hline 3PRLP 3 & 0.114 & 0.143 & 0.083 & 0.122 & 0.093 & 0.123 & 0.105 & 0.142 & 0.089 & 0.118 & 0.097 & 0.133 & 0.1 & & 0.138 & 0.121 & 0.160 \\
\hline 3PRLP 4 & 0.087 & 0.120 & 0.105 & 0.140 & 0.105 & 0.135 & 0.074 & 0.101 & 0.089 & 0.123 & 0.082 & 0.113 & 0.1 & & 0.149 & 0.061 & 0.091 \\
\hline 3PRLP 5 & 0.079 & 0.116 & 0.093 & 0.120 & 0.095 & 0.129 & 0.091 & 0.128 & 0.100 & 0.130 & 0.091 & 0.127 & 0.0 & & 0.116 & 0.087 & 0.124 \\
\hline 3PRLP 6 & 0.095 & 0.133 & 0.087 & 0.122 & 0.109 & 0.155 & 0.099 & 0.130 & 0.094 & 0.125 & 0.101 & 0.145 & 0.1 & & 0.140 & 0.098 & 0.137 \\
\hline 3PRLP 7 & 0.085 & 0.114 & 0.114 & 0.149 & 0.082 & 0.111 & 0.099 & 0.128 & 0.094 & 0.130 & 0.058 & 0.097 & $0 .($ & & 0.114 & 0.137 & 0.178 \\
\hline 3PRLP 8 & 0.089 & 0.122 & 0.089 & 0.120 & 0.078 & 0.119 & 0.128 & 0.152 & 0.096 & 0.127 & 0.135 & 0.167 & 0.1 & & 0.136 & 0.100 & 0.143 \\
\hline 3PRLP 9 & 0.095 & 0.128 & 0.103 & 0.130 & 0.091 & 0.121 & 0.107 & 0.138 & 0.112 & 0.148 & 0.082 & 0.119 & 0.0 & & 0.123 & 0.098 & 0.132 \\
\hline Alternatives & \multicolumn{2}{|c|}{$\begin{array}{l}\text { Voice Of } \\
\text { Customer }\end{array}$} & \multicolumn{3}{|c|}{$\begin{array}{c}\text { Respect For The } \\
\text { Policy }\end{array}$} & \multicolumn{2}{|c|}{ Reputation } & \multicolumn{2}{|c|}{ Operational Risk } & \multicolumn{2}{|c|}{$\begin{array}{c}\text { Organizational } \\
\text { Risk }\end{array}$} & \multicolumn{4}{|c|}{ Financial Risk } & \multicolumn{2}{|c|}{ Safety } \\
\hline 3PRLP 1 & 0.111 & 0.147 & 0.0 & & & 0.099 & 0.128 & 0.113 & 0.141 & 0.096 & 0.147 & & & & & 0.127 & 0.153 \\
\hline 3PRLP 2 & 0.092 & 0.130 & 0.1 & & & 0.109 & 0.146 & 0.113 & 0.141 & 0.067 & 0.102 & 0.0 & & & 08 & 0.081 & 0.119 \\
\hline 3PRLP 3 & 0.069 & 0.101 & 0.1 & & & 0.104 & 0.142 & 0.053 & 0.085 & 0.069 & 0.102 & 0.1 & & & 57 & 0.117 & 0.157 \\
\hline 3PRLP 4 & 0.094 & 0.134 & 0.1 & & & 0.120 & 0.159 & 0.099 & 0.141 & 0.104 & 0.141 & 0.1 & & & 39 & 0.115 & 0.145 \\
\hline 3PRLP 5 & 0.101 & 0.128 & 0.0 & & & 0.073 & 0.104 & 0.119 & 0.154 & 0.076 & 0.112 & 0.0 & & & 22 & 0.097 & 0.131 \\
\hline 3PRLP 6 & 0.094 & 0.132 & 0.0 & & & 0.073 & 0.099 & 0.113 & 0.149 & 0.102 & 0.145 & 0.1 & & & 45 & 0.044 & 0.075 \\
\hline 3PRLP 7 & 0.096 & 0.126 & 0.1 & & & 0.106 & 0.130 & 0.087 & 0.117 & 0.084 & 0.114 & 0.0 & & & 06 & 0.073 & 0.103 \\
\hline 3PRLP 8 & 0.084 & 0.126 & 0.0 & & & 0.051 & 0.080 & 0.071 & 0.105 & 0.145 & 0.178 & 0.1 & & & 51 & 0.081 & 0.115 \\
\hline 3PRLP 9 & 0.103 & 0.134 & 0.0 & & & 0.119 & 0.159 & 0.083 & 0.117 & 0.094 & 0.122 & 0.0 & & & 12 & 0.119 & 0.145 \\
\hline
\end{tabular}


Table 13. Weighted normalized gray decision matrix with evaluation 3PRLPs (Alternatives) and criteria.

\begin{tabular}{|c|c|c|c|c|c|c|c|c|c|c|c|c|c|c|c|c|}
\hline \multirow{2}{*}{$\begin{array}{c}\text { Alternatives } \\
\text { 3PRLP } 1\end{array}$} & \multicolumn{2}{|c|}{ Quality } & \multicolumn{2}{|c|}{ Cost } & \multicolumn{2}{|c|}{ Lead Time } & \multicolumn{2}{|c|}{ Delivery } & \multicolumn{2}{|c|}{ Services } & \multicolumn{2}{|c|}{$\begin{array}{c}\text { Capability of R } \\
\text { \& D } \\
\end{array}$} & \multicolumn{2}{|c|}{ Green Design } & \multicolumn{2}{|c|}{ Reuse } \\
\hline & 0.007 & 0.009 & 0.010 & 0.014 & 0.007 & 0.010 & 0.006 & 0.009 & 0.007 & 0.010 & 0.005 & 0.007 & 0.004 & 0.006 & 0.006 & 0.008 \\
\hline 3PRLP 2 & 0.007 & 0.010 & 0.007 & 0.011 & 0.005 & 0.008 & 0.005 & 0.007 & 0.007 & 0.009 & 0.007 & 0.009 & 0.006 & 0.009 & 0.007 & 0.008 \\
\hline 3PRLP 3 & 0.008 & 0.010 & 0.009 & 0.012 & 0.012 & 0.015 & 0.005 & 0.006 & 0.008 & 0.010 & 0.007 & 0.009 & 0.004 & 0.006 & 0.003 & 0.005 \\
\hline 3PRLP 4 & 0.008 & 0.011 & 0.007 & 0.010 & 0.006 & 0.010 & 0.006 & 0.008 & 0.006 & 0.009 & 0.005 & 0.007 & 0.005 & 0.007 & 0.004 & 0.006 \\
\hline 3PRLP 5 & 0.008 & 0.011 & 0.007 & 0.010 & 0.010 & 0.013 & 0.008 & 0.010 & 0.008 & 0.011 & 0.008 & 0.010 & 0.004 & 0.006 & 0.004 & 0.006 \\
\hline 3PRLP 6 & 0.013 & 0.016 & 0.009 & 0.013 & 0.011 & 0.015 & 0.006 & 0.009 & 0.008 & 0.011 & 0.006 & 0.008 & 0.007 & 0.009 & 0.005 & 0.006 \\
\hline 3PRLP 7 & 0.008 & 0.011 & 0.007 & 0.011 & 0.010 & 0.013 & 0.006 & 0.008 & 0.009 & 0.011 & 0.008 & 0.010 & 0.007 & 0.009 & 0.006 & 0.007 \\
\hline 3PRLP 8 & 0.010 & 0.013 & 0.008 & 0.012 & 0.008 & 0.013 & 0.006 & 0.009 & 0.008 & 0.010 & 0.006 & 0.009 & 0.008 & 0.010 & 0.006 & 0.008 \\
\hline 3PRLP 9 & 0.008 & 0.011 & 0.009 & 0.012 & 0.015 & 0.017 & 0.008 & 0.010 & 0.008 & 0.011 & 0.008 & 0.010 & 0.005 & 0.007 & 0.006 & 0.008 \\
\hline Alternatives & \multicolumn{2}{|c|}{ Remanufacture } & \multicolumn{2}{|c|}{ Refurbish } & \multicolumn{2}{|c|}{ Recycle } & \multicolumn{2}{|c|}{ Disposal } & \multicolumn{2}{|c|}{ Air Emissions } & \multicolumn{2}{|c|}{$\begin{array}{c}\text { Green } \\
\text { Packaging }\end{array}$} & \multicolumn{2}{|c|}{ Health } & \multicolumn{2}{|c|}{$\begin{array}{c}\text { Flexible Working } \\
\text { Arrangements }\end{array}$} \\
\hline 3PRLP 1 & 0.005 & 0.007 & 0.005 & 0.007 & 0.005 & 0.007 & 0.004 & 0.006 & 0.006 & 0.008 & 0.008 & 0.009 & 0.008 & 0.011 & 0.006 & 0.009 \\
\hline 3PRLP 2 & 0.006 & 0.008 & 0.006 & 0.007 & 0.006 & 0.008 & 0.003 & 0.005 & 0.005 & 0.006 & 0.004 & 0.006 & 0.009 & 0.012 & 0.007 & 0.011 \\
\hline 3PRLP 3 & 0.006 & 0.008 & 0.005 & 0.007 & 0.005 & 0.007 & 0.005 & 0.007 & 0.005 & 0.007 & 0.006 & 0.008 & 0.010 & 0.014 & 0.012 & 0.016 \\
\hline 3PRLP 4 & 0.005 & 0.007 & 0.006 & 0.008 & 0.006 & 0.008 & 0.004 & 0.005 & 0.005 & 0.007 & 0.005 & 0.007 & 0.012 & 0.015 & 0.006 & 0.009 \\
\hline 3PRLP 5 & 0.004 & 0.007 & 0.005 & 0.007 & 0.005 & 0.007 & 0.005 & 0.006 & 0.006 & 0.007 & 0.005 & 0.008 & 0.009 & 0.012 & 0.008 & 0.012 \\
\hline 3PRLP 6 & 0.005 & 0.008 & 0.005 & 0.007 & 0.006 & 0.009 & 0.005 & 0.007 & 0.005 & 0.007 & 0.006 & 0.009 & 0.010 & 0.014 & 0.010 & 0.013 \\
\hline 3PRLP 7 & 0.005 & 0.006 & 0.007 & 0.009 & 0.005 & 0.006 & 0.005 & 0.006 & 0.005 & 0.007 & 0.004 & 0.006 & 0.008 & 0.011 & 0.013 & 0.017 \\
\hline 3PRLP 8 & 0.005 & 0.007 & 0.005 & 0.007 & 0.005 & 0.007 & 0.006 & 0.008 & 0.005 & 0.007 & 0.008 & 0.010 & 0.010 & 0.014 & 0.010 & 0.014 \\
\hline 3PRLP 9 & 0.005 & 0.007 & 0.006 & 0.007 & 0.005 & 0.007 & 0.005 & 0.007 & 0.006 & 0.008 & 0.005 & 0.007 & 0.009 & 0.012 & 0.010 & 0.013 \\
\hline Alternatives & \multicolumn{2}{|c|}{$\begin{array}{l}\text { Voice Of } \\
\text { Customer }\end{array}$} & \multicolumn{3}{|c|}{$\begin{array}{c}\text { Respect For The } \\
\text { Policy }\end{array}$} & \multicolumn{2}{|c|}{ Reputation } & \multicolumn{2}{|c|}{ Operational Risk } & \multicolumn{2}{|c|}{$\begin{array}{c}\text { Organizational } \\
\text { Risk }\end{array}$} & \multicolumn{3}{|c|}{ Financial Risk } & \multicolumn{2}{|c|}{ Safety } \\
\hline 3PRLP 1 & 0.011 & 0.014 & 0.00 & 0. & & 0.010 & 0.013 & 0.009 & 0.011 & 0.008 & 0.012 & & & & 0.010 & 0.012 \\
\hline 3PRLP 2 & 0.009 & 0.012 & 0.01 & 0. & & 0.011 & 0.014 & 0.009 & 0.011 & 0.005 & 0.008 & 0 . & & 010 & 0.007 & 0.010 \\
\hline 3PRLP 3 & 0.007 & 0.010 & 0.01 & 0. & & 0.010 & 0.014 & 0.004 & 0.007 & 0.005 & 0.008 & 0.0 & & 015 & 0.009 & 0.013 \\
\hline 3PRLP 4 & 0.009 & 0.013 & 0.01 & 0. & & 0.012 & 0.016 & 0.008 & 0.011 & 0.008 & 0.011 & 0.0 & & 013 & 0.009 & 0.012 \\
\hline 3PRLP 5 & 0.010 & 0.012 & 0.00 & 0. & & 0.007 & 0.010 & 0.009 & 0.012 & 0.006 & 0.009 & 0.0 & & 012 & 0.008 & 0.011 \\
\hline 3PRLP 6 & 0.009 & 0.013 & 0.00 & 0. & & 0.007 & 0.010 & 0.009 & 0.012 & 0.008 & 0.011 & 0.0 & & 014 & 0.004 & 0.006 \\
\hline 3PRLP 7 & 0.009 & 0.012 & 0.01 & 0. & & 0.010 & 0.013 & 0.007 & 0.009 & 0.007 & 0.009 & 0.0 & & 010 & 0.006 & 0.008 \\
\hline 3PRLP 8 & 0.008 & 0.012 & 0.00 & & & 0.005 & 0.008 & 0.006 & 0.008 & 0.011 & 0.014 & 0.0 & & 015 & 0.007 & 0.009 \\
\hline 3PRLP 9 & 0.010 & 0.013 & 0.00 & 0. & & 0.012 & 0.016 & 0.007 & 0.009 & 0.007 & 0.010 & 0.0 & & 011 & 0.010 & 0.012 \\
\hline
\end{tabular}


Specifically, the initial gray decision matrix (Table 11) is obtained based on the ideas of experts, which are then normalized using Eqs. (5) and (6) to produce the normalized gray decision matrix in Table 12. The results are then combined with the criteria weights generated by fuzzy AHP to construct the weighted normalized gray decision matrix (Table 13) as the final matrix in the 3PRLP evaluation and selection process.

The final matrix in Table 13, together with Eqs. (11) and (12), are used to calculate the total of upside and downside criteria. The $B N G P_{k}\left(y_{k}\right)$ values are then computed to rank the 3PRLPs and results are presented in Table 14. It can be seen that the alternative number 7 ranks first and 3PRLP 2 is the second-best alternative. The alternative numbers 9, 4, 3, 5, 8, 6 and 1 rank from third to ninth, respectively.

Table 14. Best non-gray performance value with MOORA-G and 3PRLPs ranking.

\begin{tabular}{|c|c|c|c|c|c|c|c|c|}
\hline Alternatives & \multicolumn{2}{|c|}{$\mathbf{V}_{\mathbf{k j}+}$} & \multicolumn{2}{|c|}{$\mathbf{V}_{\mathbf{k j}-}$} & \multicolumn{2}{c|}{$\left(\mathbf{y}_{\mathbf{k}}\right)$} & BNGP $_{\mathbf{k}}\left(\mathbf{y}_{\mathbf{k}}\right)$ & RANK \\
\hline 3PRLP 1 & 0.115 & 0.157 & 0.048 & 0.066 & 0.066 & 0.091 & 0.0787 & $\mathbf{9}$ \\
\hline 3PRLP 2 & 0.117 & 0.161 & 0.038 & 0.055 & 0.079 & 0.107 & 0.0930 & $\mathbf{2}$ \\
\hline 3PRLP 3 & 0.120 & 0.164 & 0.046 & 0.064 & 0.074 & 0.099 & 0.0868 & $\mathbf{5}$ \\
\hline 3PRLP 4 & 0.122 & 0.163 & 0.044 & 0.062 & 0.078 & 0.101 & 0.0894 & $\mathbf{4}$ \\
\hline 3PRLP 5 & 0.115 & 0.159 & 0.046 & 0.063 & 0.069 & 0.096 & 0.0824 & $\mathbf{6}$ \\
\hline 3PRLP 6 & 0.120 & 0.164 & 0.053 & 0.072 & 0.067 & 0.092 & 0.0793 & $\mathbf{8}$ \\
\hline 3PRLP 7 & 0.126 & 0.166 & 0.042 & 0.059 & 0.083 & 0.107 & 0.0952 & $\mathbf{1}$ \\
\hline 3PRLP 8 & 0.119 & 0.163 & 0.050 & 0.068 & 0.069 & 0.094 & 0.0816 & $\mathbf{7}$ \\
\hline 3PRLP 9 & 0.127 & 0.170 & 0.051 & 0.067 & 0.076 & 0.103 & 0.0898 & $\mathbf{3}$ \\
\hline
\end{tabular}

\subsection{Discussion}

To validate and benchmark the obtained results from MOORA-G, we apply the MOORA method to the case and its results are shown in Table 15. Figure 4 further illustrates the ranking differences and similarities of both methods graphically.

Table 15. Best non-gray performance value with MOORA and 3PRLPs ranking.

\begin{tabular}{|c|c|c|c|c}
\hline Alternatives & $\mathbf{V}_{\mathbf{k j}+}$ & $\mathbf{V}_{\mathbf{k j}-}$ & $\mathbf{B N P}_{\mathbf{k}}$ & RANK \\
\hline 3PRLP 1 & 0.165 & 0.118 & 0.047 & $\mathbf{5}$ \\
\hline 3PRLP 2 & 0.172 & 0.123 & 0.049 & $\mathbf{3}$ \\
\hline 3PRLP 3 & 0.167 & 0.125 & 0.042 & $\mathbf{8}$ \\
\hline 3PRLP 4 & 0.172 & 0.124 & 0.048 & $\mathbf{4}$ \\
\hline 3PRLP 5 & 0.162 & 0.118 & 0.044 & $\mathbf{7}$ \\
\hline 3PRLP 6 & 0.161 & 0.123 & 0.038 & $\mathbf{9}$ \\
\hline 3PRLP 7 & 0.174 & 0.122 & 0.052 & $\mathbf{1}$ \\
\hline 3PRLP 8 & 0.167 & 0.121 & 0.046 & $\mathbf{6}$ \\
\hline 3PRLP 9 & 0.169 & 0.118 & 0.051 & $\mathbf{2}$ \\
\hline
\end{tabular}




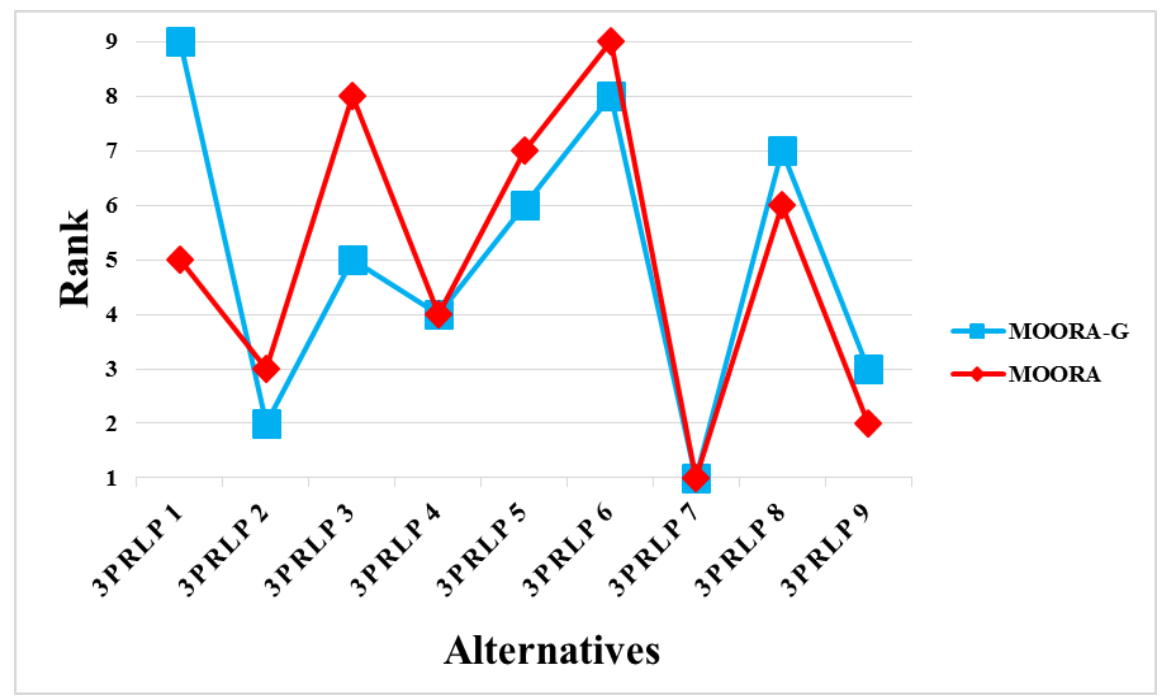

Figure 4. Rankings of the alternatives (3PRLPs).

It should be stressed that 3PRLP 7 is selected as the best alternative. Air emissions, services, flexible working arrangements, respect for policy and reputation are among the criteria that have the greatest impact to enable 3PRLP 7 to be the number one. This means that, based on the ideas of the experts, criteria related to the social dimension are more significant for this alternative, while the other dimensions are important too, such as environmental aspect as mentioned earlier. The criteria of lead time, air emissions, services, flexible working arrangements and the organizational risk position 3PRLP 2 to be the second-best alternative. However, with MOORA method this rank is obtained for the 3PRLP 9. The ranking results show, in this case, that the air emissions criterion has a big impact on the best and second-best alternative. Regardless of the goods and filed of production, air emissions probably is one of the most significant and biggest problems in the current production world. The selection results in this case study show that the proposed hybrid decision-making method can faithfully transfer the ideas of the participated experts to the results of the final decision. On the other end of the ranking spectrum, the 3PRLP 1 is the worst alternative among the nine alternatives with MOORA-G method. Cost, green design, disposal, operational risk criteria have a dramatic effect on the rank of this alternative. Hence, there lacks attention to green and environmental issues in experts' comments owing to the fact that, in both the best and the worst choices, environmental criteria have the least effect. This is a considerable point which calls for decision-makers and industrial experts to pay more attention to nature and environmental issues. In addition, 3PRLP 6 ranks the second last with MOORA-G method under the major impact of cost, lead time, financial risk and safety criteria, despite the fact that this alternative is the worst alternative ranked by the MOORA method and 3PRLP 3 is the second-worst with the MOORA method. In contrast of the best alternatives, these worst alternatives suffer from weakness regarding the environmental criteria, specifically air emissions, as a result of the fact that the experts were motivated to allocate scores based on the content of reverse logistics and environmental issues.

Overall, a glance at Figure 4 illustrates that the trend of both curves for the two methods are extremely similar in such a way that there are two mutual choices about 3PRLP 7 as the best one and 3PRLP 4 at the fourth rank, also there are five choices with just a rank variance. Nevertheless, there are overwhelming distances between the two methods for 3PRLPs 1 and 3. 
According to the analysis and experts' ideas, since we have several criteria with qualitative nature and uncertainty in this problem (selection), the MOORA-G method's performance is more viable than the MOORA method. This is attributed to the gray relations determining an interval, involving lower and upper limits, for each point which not only helps to deal with uncertainty but also transforms qualitative criteria into quantitative ones. Consequently, the proposed MOORA-G offers a wider range of applications and is more suitable than the MOORA method. Moreover, the results clearly reflect the fact that the experts focused on the environmental criteria more than other criteria, and these criteria have a considerable impact on the results. Indeed, the majority of the environmental criteria are qualitative and based on the experts' judgment, which are beyond what the MOORA method could handle. Consequently, it is inevitable that the proposed hybrid method combining fuzzy AHP with MOORA-G outperforms the results of the conventional MOORA approach. This is an important feature of the hybrid approach because most environmental and social criteria, which are the basis of cleaner production and sustainable development, are qualitative and involve uncertainty.

\section{Managerial Implications}

Selecting a suitable 3PRLP involves a considerable ranking process, which usually covers multiple selection criteria. Oftentimes, these selection criteria include qualitative ones, or simply just preferences of the decision-makers. With such a demanding task, the proposed MOORA-G demonstrates its viability in dealing with the qualitative and uncertain inputs and offers robust recommendations.

As demonstrated in this paper, the case company can select the best 3PRLP, and balance across a wide spectrum of selection criteria. Indeed, due to the multi-facet nature of reverse logistics operations, there usually are a large set of potential selection criteria involved in the selection process. This subsequently makes the selection process a very complex one. Therefore, one strong aspect of the proposed hybrid approach is that it can automatically calculate the weights assigned to each of the selection criteria. Another notable feature of the proposed method is that it can handle qualitative and uncertain inputs.

In the meantime, the case company can also identify the strengths and weaknesses of each service provider, which then could be used to request the selected service provider to improve on certain areas, or ask sub-optimal service providers to improve so that they could qualify for future selection. This will not only help improve the service levels of 3PRLPs as an industry, but also ensure that the clients of 3PRLPs can build quality supplier pools to drive cost down without sacrificing the service quality in the long run.

Without loss of generality, the approach proposed in this paper would be equally applicable to other problems and other industries. The approach can also be used as a benchmarking tool for service providers in guiding their adjustments to the operations and strategic directions, so that they can better align with customer and societal expectations. At the same time, governments and regulatory bodies can utilize the proposed approach to examine the relationships among economic, environmental, and social issues, and use the results to persuade and encourage stronger law and policy enforcement on the sustainability front. 


\section{Conclusion and Future Directions}

In this research, a novel hybrid MADM approach, which combined fuzzy AHP and MOORA-G, was proposed and applied to a case study where 3PRLPs were evaluated and selected. The fuzzy AHP was used for weighting the considered criteria and determine the amount of influence of these criteria over the dceision process, which were then passed to and handled by the developed MOORA-G to recommend the final ranking. In the process, the MOORA method was developed to handle gray relations for the first time to address the challenge brought by uncertain and qualitative inputs.

The proposed hybrid method was applied in a case study in car parts manufacturing industry to check the applicability and validity, and the results were benchmarked with the MOORA method. While both MOORA and MOORA-G selected the same best 3PRLP, our proposed approach showed to be more versatile in dealing with qualitative and uncertain inputs. The obtained results successfully addressed the selection criteria in a sustainable manner, and balanced economic, environmetnal and social dimensions in the presence of risk and safety criteria. The application process and the results highlighted the capability of the proposed hybrid approach in handling multi-fact dimensions of evaluation criteria and dealing qualitative and uncertain inputs.

The proposed method could be extended to a few directions. Firstly, it would be helpful to see whether the suggested hybrid approach applies well in other industries like appliances, glasses, paper for 3PRLP selection and beyond, such as supplier and market selection. Secondly, it would be beneficial to benchmark with other MADM methods like VIKOR, TOPSIS, etc. to check the validity and consistency of our proposed approach. Thirdly, future research can focus on increasing the number of criteria in order to improve the accuracy and precision of selection and evaluation.

\section{References}

Abdi, F. (2018). Hospital leanness assessment model: A Fuzzy MULTI-MOORA decision making approach. Journal of Industrial and Systems Engineering, 11(3), 37-59.

Abdulshahed, A. M., Badi, I. A., \& Blaow, M. M. (2017). A grey-based decision-making approach to the supplier selection problem in a steelmaking company: A case study in Libya. Grey Systems: Theory and Application, 7(3), 385-396.

Aghdaie, M. H., Zolfani, S. H., \& Zavadskas, E. K. (2013). Market segment evaluation and selection based on application of fuzzy AHP and COPRAS-G methods. Journal of Business Economics and Management, 14(1), 213-233.

Agrawal, S., Singh, R. K., \& Murtaza, Q. (2016). Disposition decisions in reverse logistics: Graph theory and matrix approach. Journal of Cleaner Production, 137, 93-104.

Akkaya, G., Turanoğlu, B., \& Öztaş, S. (2015). An integrated fuzzy AHP and fuzzy MOORA approach to the problem of industrial engineering sector choosing. Expert Systems with Applications, 42(24), 9565-9573.

Arabsheybani, A., Paydar, M. M., \& Safaei, A. S. (2018). An integrated fuzzy MOORA method and FMEA technique for sustainable supplier selection considering quantity discounts and supplier's risk. Journal of Cleaner Production, 190, 577-591. 
Archana, M., \& Sujatha, V. (2012). Application of fuzzy moora and gra in multi-criterion decision making problems. International Journal of Computer Applications, 53(9).

Attri, R., \& Grover, S. (2014). Decision making over the production system life cycle: MOORA method. International Journal of System Assurance Engineering and Management, 5(3), 320-328.

Awasthi, A., \& Kannan, G. (2016). Green supplier development program selection using NGT and VIKOR under fuzzy environment. Computers \& Industrial Engineering, 91, 100-108.

Azadi, M., \& Saen, R. F. (2011). A new chance-constrained data envelopment analysis for selecting third-party reverse logistics providers in the existence of dual-role factors. Expert Systems with Applications, 38(10), 12231-12236.

Bai, C., \& Sarkis, J. (2019). Integrating and extending data and decision tools for Sustainable third-party reverse logistics provider selection. Computers \& Operations Research, 110, 188-207.

Baležentis, A., Baležentis, T., \& Brauers, W. K. (2012). Personnel selection based on computing with words and fuzzy MULTIMOORA. Expert Systems with Applications, 39(9), 7961-7967.

Bianchini, A. (2018). 3PL provider selection by AHP and TOPSIS methodology. Benchmarking: An International Journal, 25(1), 235-252.

Brauers, W. K. M. (2013). Multi-objective seaport planning by MOORA decision making. Annals of Operations Research, 206(1), 39-58.

Brauers, W. K. M., Zavadskas, E. K., Peldschus, F., \& Turskis, Z. (2008). Multi-objective optimization of road design alternatives with an application of the MOORA method. Proceedings of the $25^{\text {th }}$ International Symposium on Automation and Robotics in Construction, 541-548.

Brauers,W. K. M., Zavadskas, E. K. (2006). The MOORA method and its application to privatization in a transition economies. Control and Cybernetics, 35(2), 445-469.

Brauers, W. K., \& Zavadskas, E. K. (2009). Robustness of the multi-objective MOORA method with a test for the facilities sector. Technological and Economic Development of Economy, 15(2), 352-375.

Bouzon, M., Govindan, K., Rodriguez, C. M. T., \& Campos, L. M. (2016). Identification and analysis of reverse logistics barriers using fuzzy Delphi method and AHP. Resources, Conservation and Recycling, 108, 182-197.

Chakraborty, S. (2011). Applications of the MOORA method for decision making in manufacturing environment. The International Journal of Advanced Manufacturing Technology, 54(9-12), 1155-1166.

Chand, M., Bhatia, N., \& Singh, R. K. (2018). ANP-MOORA-based approach for the analysis of selected issues of green supply chain management. Benchmarking: An International Journal, 25(2), 642-659. 
Chang, D. Y. (1992). Extent analysis and synthetic decision. Optimization Techniques and Applications, 1(1), 352-355.

Cheng, Y. H., \& Lee, F. (2010). Outsourcing reverse logistics of high-tech manufacturing firms by using a systematic decision-making approach: TFT-LCD sector in Taiwan. Industrial Marketing Management, 39(7), 1111-1119.

Chiu, Y., Lin, P. C., \& Hsu, H. H. (2011). Considering third-party logistics providers in reverse logistics. Journal of the Chinese Institute of Industrial Engineers, 28(7), 512-520.

Da Silveira Guimarães, J. L., \& Salomon, V. A. P. (2015). ANP applied to the evaluation of performance indicators of reverse logistics in footwear industry. Procedia Computer Science, 55, 139-148.

Das, M. C., Sarkar, B., \& Ray, S. (2013). On the performance of Indian technical institutions: a combined SOWIA-MOORA approach. Opsearch, 50(3), 319-333.

Dincer, H. (2015). Profit-based stock selection approach in banking sector using Fuzzy AHP and MOORA method. Global Business and Economics Research Journal, 4(2), 1-26.

Dinçer, H., Yuksel, S., \& Bozaykut-Buk, T. (2018). Evaluation of Financial and Economic Effects on Green Supply Chain Management With Multi-Criteria Decision-Making Approach: Evidence From Companies Listed in BIST. In Handbook of Research on Supply Chain Management for Sustainable Development (pp. 144-175). IGI Global.

dos Santos, B. M., Godoy, L. P., \& Campos, L. M. (2019). Performance evaluation of green suppliers using entropy-TOPSIS-F. Journal of Cleaner Production, 207, 498-509.

Efendigil, T., Önüt, S., \& Kongar, E. (2008). A holistic approach for selecting a third-party reverse logistics provider in the presence of vagueness. Computers \& Industrial Engineering, 54(2), 269-287.

El-Santawy, M. F., \& El-Dean, R. A. Z. (2012). Selection of a consulting firm by using SDVMOORA. Life Science Journal, 9(2s), 126-128.

El-Santawy, M. F., \& Ahmed, A. N. (2012a). Analysis of project selection by using SDVMOORA approach. Life Science Journal, 9(2s), 129-131.

El-Santawy, M. F., \& Ahmed, A. N. (2012b). Analysis of project selection by using SDVMOORA approach. Life Science Journal, 9(2), 123-125.

Farzipoor Saen, R. (2009). A mathematical model for selecting third-party reverse logistics providers. International Journal of Procurement Management, 2(2), 180-190.

Gadakh, V. S. (2010). Application of MOORA method for parametric optimization of milling process. International Journal of Applied Engineering Research, 1(4), 743.

Garetti, M., \& Taisch, M. (2012). Sustainable manufacturing: trends and research challenges. Production Planning \& Control, 23(2-3), 83-104.

Ghoushchi, S. J., Yousefi, S., \& Khazaeili, M. (2019). An extended FMEA approach based on the Z-MOORA and fuzzy BWM for prioritization of failures. Applied Soft Computing, 81, 105505. 
Goebel, P., Reuter, C., Pibernik, R., \& Sichtmann, C. (2012). The influence of ethical culture on supplier selection in the context of sustainable sourcing. International Journal of Production Economics, 140(1), 7-17.

Gorener, A., Dincer, H., \& Hacioglu, U. (2013). Application of multi-objective optimization on the basis of ratio analysis (MOORA) method for bank branch location selection. International Journal of Finance and Banking Studies, 2(2), 41-52.

Govindan, K., \& Soleimani, H. (2017). A review of reverse logistics and closed-loop supply chains: a Journal of Cleaner Production focus. Journal of Cleaner Production, 142, 371-384.

Govindan, K., Agarwal, V., Darbari, J. D., \& Jha, P. C. (2017). An integrated decision making model for the selection of sustainable forward and reverse logistic providers. Annals of Operations Research, 1-44.

Govindan, K., Palaniappan, M., Zhu, Q., \& Kannan, D. (2012). Analysis of third party reverse logistics provider using interpretive structural modeling. International Journal of Production Economics, 140(1), 204-211.

Govindan, K., Sarkis, J., \& Palaniappan, M. (2013). An analytic network process-based multicriteria decision making model for a reverse supply chain. The International Journal of Advanced Manufacturing Technology, 68(1-4), 863-880.

Govindan, K., Kadziński, M., Ehling, R., \& Miebs, G. (2018). Selection of a sustainable thirdparty reverse logistics provider based on the robustness analysis of an outranking graph kernel conducted with ELECTRE I and SMAA. Omega. DOI: 10.1016/j.omega.2018.05.007

Govindan, K., Jha, P. C., Agarwal, V., \& Darbari, J. D. (2019). Environmental management partner selection for reverse supply chain collaboration: A sustainable approach. Journal of Environmental Management, 236, 784-797.

Guarnieri, P., Sobreiro, V. A., Nagano, M. S., \& Serrano, A. L. M. (2015). The challenge of selecting and evaluating third-party reverse logistics providers in a multicriteria perspective: a Brazilian case. Journal of Cleaner Production, 96, 209-219.

Gupta, V., Kapur, P. K., \& Kumar, D. (2017). Measuring and evaluating data distribution strategies using an integrated approach of fuzzy based MOORA and AHP. Life Cycle Reliability and Safety Engineering, 6(1), 37-45.

Hsueh, J. T., \& Lin, C. Y. (2015). Constructing a network model to rank the optimal strategy for implementing the sorting process in reverse logistics: case study of photovoltaic industry. Clean Technologies and Environmental Policy, 17(1), 155-174.

İç, Y. T. (2019). A Multi-Objective Credit Evaluation Model Using MOORA Method and Goal Programming. Arabian Journal for Science and Engineering, 1-14.

Ilgin, M. A. (2017). An integrated methodology for the used product selection problem faced by third-party reverse logistics providers. International Journal of Sustainable Engineering, 10(6), 399-410. 
Jain, V., \& Khan, S. A. (2017). Application of AHP in reverse logistics service provider selection: a case study. International Journal of Business Innovation and Research, 12(1), 94-119.

Jayant, A., Gupta, P., Garg, S. K., \& Khan, M. (2014). TOPSIS-AHP based approach for selection of reverse logistics service provider: a case study of mobile phone industry. Procedia Engineering, 97, 2147-2156.

John, S. T., Sridharan, R., \& Kumar, P. R. (2018). Reverse logistics network design: a case of mobile phones and digital cameras. The International Journal of Advanced Manufacturing Technology, 94(1-4), 615-631.

Kafa, N., Hani, Y., \& El Mhamedi, A. (2014). A Fuzzy Multi Criteria Approach for Evaluating Sustainability Performance of Third-Party Reverse Logistics Providers. In IFIP International Conference on Advances in Production Management Systems (pp. 270-277). Springer, Berlin, Heidelberg.

Kalirasu, S., Rajini, N., Rajesh, S., Jappes, J. W., \& Karuppasamy, K. (2017). AWJM Performance of jute/polyester composite using MOORA and analytical models. Materials and Manufacturing Processes, 32(15), 1730-1739.

Kannan, D., Garg, K., Jha, P. C., \& Diabat, A. (2017). Integrating disassembly line balancing in the planning of a reverse logistics network from the perspective of a third party provider. Annals of Operations Research, 253(1), 353-376.

Kannan, G., Pokharel, S., \& Kumar, P. S. (2009). A hybrid approach using ISM and fuzzy TOPSIS for the selection of reverse logistics provider. Resources, Conservation and Recycling, 54(1), 28-36.

Karande, P., \& Chakraborty, S. (2012a). Application of multi-objective optimization on the basis of ratio analysis (MOORA) method for materials selection. Materials \& Design, 37, 317-324.

Karande, P., \& Chakraborty, S. (2012b). Decision making for supplier selection using the MOORA method. IUP Journal of Operations Management, 11(2), 6.

Karande, P., \& Chakraborty, S. (2012c). A Fuzzy-MOORA approach for ERP system selection. Decision Science Letters, 1(1), 11-21.

Kecek, G. and Demirag, F. (2016) A Comparative Analysis of TOPSIS and MOORA in Laptop Selection. Research on Humanities and Social Sciences, 6(14), 1-9.

Keshavarz Ghorabaee, M., Amiri, M., Kazimieras Zavadskas, E., \& Antuchevičienė, J. (2017). Assessment of third-party logistics providers using a CRITIC-WASPAS approach with interval type-2 fuzzy sets. Transport, 32(1), 66-78.

Kundakci, N. (2016). Combined multi-criteria decision making approach based on MACBETH and MULTI-MOORA methods. Alphanumeric Journal, 4(1), 17-26.

Kuşakcı, A. O., Ayvaz, B., Cin, E., \& Aydın, N. (2019). Optimization of reverse logistics network of End of Life Vehicles under fuzzy supply: A case study for Istanbul Metropolitan Area. Journal of Cleaner Production, 215, 1036-1051. 
Li, G. D., Yamaguchi, D., \& Nagai, M. (2007). A grey-based decision-making approach to the supplier selection problem. Mathematical and Computer Modelling, 46(3-4), 573-581.

Li, W., Wu, H., Jin, M., \& Lai, M. (2017). Two-stage remanufacturing decision makings considering product life cycle and consumer perception. Journal of Cleaner Production, 161, 581-590.

Li, Y., Kannan, D., Garg, K., Gupta, S., Gandhi, K., \& Jha, P. C. (2018a). Business orientation policy and process analysis evaluation for establishing third party providers of reverse logistics services. Journal of Cleaner Production, 182, 1033-1047.

Li, Y. L., Ying, C. S., Chin, K. S., Yang, H. T., \& Xu, J. (2018b). Third-party Reverse Logistics Provider Selection Approach Based on Hybrid-Information MCDM and Cumulative Prospect Theory. Journal of Cleaner Production. DOI: 10.1016/j.jclepro.2018.05.213

Liu, A., Ji, X., Lu, H., \& Liu, H. (2019). The selection of 3PRLs on self-service mobile recycling machine: Interval-valued pythagorean hesitant fuzzy best-worst multi-criteria group decision-making. Journal of Cleaner Production, 230, 734-750.

Mahmoudzadeh, M., Mansour, S., \& Karimi, B. (2013). To develop a third-party reverse logistics network for end-of-life vehicles in Iran. Resources, Conservation and Recycling, $78,1-14$.

Majumder, H., \& Maity, K. (2017). Optimization of machining condition in WEDM for titanium grade 6 using MOORA coupled with PCA - a multivariate hybrid approach. Journal of Advanced Manufacturing Systems, 16(02), 81-99.

Majumder, H., \& Maity, K. (2018). Prediction and optimization of surface roughness and micro-hardness using grnn and MOORA-fuzzy-a MCDM approach for nitinol in WEDM. Measurement, 118, 1-13.

Masten, K. A., \& Kim, S. L. (2015). So many mechanisms, so little action: The case for 3rd party supply chain coordination. International Journal of Production Economics, 168, 1320 .

Matawale, C. R., Datta, S., \& Mahapatra, S. S. (2016). Supplier selection in agile supply chain: Application potential of FMLMCDM approach in comparison with Fuzzy-TOPSIS and Fuzzy-MOORA. Benchmarking: An International Journal, 23(7), 2027-2060.

Mavi, R. K., Goh, M., \& Zarbakhshnia, N. (2017). Sustainable third-party reverse logistic provider selection with fuzzy SWARA and fuzzy MOORA in plastic industry. The International Journal of Advanced Manufacturing Technology, 91(5-8), 2401-2418.

Mitra, S., Karathanasopoulos, A., Sermpinis, G., Dunis, C., Hood, J. (2015). Operational risk: Emerging markets, sectors and measurement. European Journal of Operational Research. 241(1), 122-132.

Momeni, E., Azadi, M., \& Saen, R. F. (2015). Measuring the efficiency of third party reverse logistics provider in supply chain by multi objective additive network DEA model. International Journal of Shipping and Transport Logistics, 7(1), 21-41. 
Ni, J., Chu, L., Yen, B, P, C. (2016). Coordinating operational policy with financial hedging for risk-averse firms. Omega. 59, Part B, 279-289.

Önay, O. (2016). Multi-Criteria Assessment of Better Life via TOPSIS and MOORA Methods. International Journal of Business and Social Science, 7(1), 225-234.

Ozcelik, G., Aydoğan, E., \& Gencer, C. (2014). A hybrid moora-fuzzy algorithm for special education and rehabilitation center selection. Journal of Management and Information Science, 2(3), 53-62.

Peretti, U., Tatham, P., Wu, Y., \& Sgarbossa, F. (2015). Reverse logistics in humanitarian operations: Challenges and opportunities. Journal of Humanitarian Logistics and Supply Chain Management, 5(2), 253-274.

Pérez-Domínguez, L., Alvarado-Iniesta, A., Rodríguez-Borbón, I., \& Vergara-Villegas, O. (2015). Intuitionistic fuzzy MOORA for supplier selection. Dyna, 82(191), 34-41.

Pérez-Domínguez, L., Rodríguez-Picón, L. A., Alvarado-Iniesta, A., Luviano Cruz, D., \& Xu, Z. (2018). MOORA under Pythagorean fuzzy set for multiple criteria decision making. Complexity, 2018.

Perçin, S. (2019). An integrated fuzzy SWARA and fuzzy AD approach for outsourcing provider selection. Journal of Manufacturing Technology Management, 30(2), 531-552.

Prajapati, H., Kant, R., \& Shankar, R. (2018). Bequeath life to death: State-of-art review on reverse logistics. Journal of Cleaner Production.

Prakash, C., \& Barua, M. K. (2016a). A combined MCDM approach for evaluation and selection of third-party reverse logistics partner for Indian electronics industry. Sustainable Production and Consumption, 7, 66-78.

Prakash, C., \& Barua, M.K. (2016b). An analysis of integrated robust hybrid model for thirdparty reverse logistics partner selection under fuzzy environment. Resources, Conservation and Recycling. 108, 63-81.

Rogers, D. S., \& Tibben-Lembke, R. S. (1999). Going backwards: reverse logistics trends and practices (Vol. 2). Pittsburgh, PA: Reverse Logistics Executive Council.

Saaty, T. L. (1980). The Analytic Hierarchy Process. New York, NY: McGraw-Hill.

Saen, R. F. (2010). A new model for selecting third-party reverse logistics providers in the presence of multiple dual-role factors. The International Journal of Advanced Manufacturing Technology, 46(1-4), 405-410.

Sahu, A. K., Sahu, N. K., \& Sahu, A. K. (2014). Appraisal of CNC machine tool by integrated MULTI-MOORA-IVGN circumferences: An empirical study. Grey Systems: Theory and Application, 4(1), 104-123.

Sahu, A. K., Sahu, N. K., \& Sahu, A. K. (2016). Application of modified MULTI-MOORA for CNC machine tool evaluation in IVGTFNS environment: an empirical study. International Journal of Computer Aided Engineering and Technology, 8(3), 234-259. 
Samantra, C., Sahu, N. K., Datta, S., \& Mahapatra, S. S. (2013). Decision-making in selecting reverse logistics alternative using interval-valued fuzzy sets combined with VIKOR approach. International Journal of Services and Operations Management, 14(2), 175-196.

Santos, F. J., \& Camargo, H. A. (2010). Fuzzy systems for multicriteria decision making. CLEI Electronic Journal, 13(3), 1-8.

Sarkar, A., Panja, S. C., Das, D., \& Sarkar, B. (2015). Developing an efficient decision support system for non-traditional machine selection: an application of MOORA and MOOSRA. Production \& Manufacturing Research, 3(1), 324-342.

Sasikumar, P., \& Haq, A. N. (2011). Integration of closed loop distribution supply chain network and 3PRLP selection for the case of battery recycling. International Journal of Production Research, 49(11), 3363-3385.

Senthil, S., Srirangacharyulu, B., Ramesh, A. (2014). A robust hybrid multi-criteria decision making methodology for contractor evaluation and selection in third-party reverse logistics. Expert Systems with Applications. 41(1), 50-58.

Siddiqui, Z., \& Tyagi, K. (2016). Application of fuzzy-MOORA method: ranking of components for reliability estimation of component-based software systems. Decision Science Letters, 5(1), 169-188.

Soleimani, H., \& Govindan, K. (2014). Reverse logistics network design and planning utilizing conditional value at risk. European Journal of Operational Research, 237(2), 487-497.

Stanujkic, D. (2013). An extension of the MOORA method for solving fuzzy decision making problems. Technological and Economic Development of Economy, 19(sup1), S228-S255.

Suyabatmaz, A. Ç., Altekin, F. T., \& Şahin, G. (2014). Hybrid simulation-analytical modeling approaches for the reverse logistics network design of a third-party logistics provider. Computers \& Industrial Engineering, 70, 74-89.

Tansel İç, Y., \& Yıldırım, S. (2013). MOORA-based Taguchi optimisation for improving product or process quality. International Journal of Production Research, 51(11), 33213341 .

Tavana, M., Zareinejad, M., Di Caprio, D., \& Kaviani, M. A. (2016a). An integrated intuitionistic fuzzy AHP and SWOT method for outsourcing reverse logistics. Applied Soft Computing, 40, 544-557.

Tavana, M., Zareinejad, M., Santos-Arteaga, F. J., \& Kaviani, M. A. (2016b). A conceptual analytic network model for evaluating and selecting third-party reverse logistics providers. The International Journal of Advanced Manufacturing Technology, 86(5-8), 1705-1721.

Tian, G., Liu, X., Zhang, M., Yang, Y., Zhang, H., Lin, Y., Ma, F., Wang, X., Qu, T. \& Li, Z. (2019). Selection of take-back pattern of vehicle reverse logistics in China via GreyDEMATEL and Fuzzy-VIKOR combined method. Journal of Cleaner Production, 220, 1088-1100. 
Tosarkani, B. M., \& Amin, S. H. (2018). A multi-objective model to configure an electronic reverse logistics network and third party selection. Journal of Cleaner Production, 198, 662682 .

Turki, S., Sauvey, C., \& Rezg, N. (2018). Modelling and optimization of a manufacturing/remanufacturing system with storage facility under carbon cap and trade policy. Journal of Cleaner Production, 193, 441-458.

Van Laarhoven, P. J. M., \& Pedrycz, W. (1983). A fuzzy extension of Saaty's priority theory. Fuzzy Sets and Systems, 11(1-3), 229-241.

Wang, J., \& Zhu, Y. (2012). Research on third-party reverse logistics provider selection based on fuzzy clustering in perspective of low-carbon economy. Communications in Information Science and Management Engineering, 2(2).

Wang, H., Jiang, Z., Zhang, H., Wang, Y., Yang, Y., \& Li, Y. (2019). An integrated MCDM approach considering demands-matching for reverse logistics. Journal of Cleaner Production, 208, 199-210.

Wierzbicki, A. (1984). Interactive decision analysis and interpretative computer intelligence. In Interactive Decision Analysis (pp. 2-19). Springer, Berlin, Heidelberg.

Yu, H., \& Solvang, W. D. (2018). Incorporating flexible capacity in the planning of a multiproduct multi-echelon sustainable reverse logistics network under uncertainty. Journal of Cleaner Production, 198, 285-303.

Yüksel, S., Dinçer, H., \& Emir, Ş. (2017). Comparing the performance of Turkish deposit banks by using DEMATEL, Grey Relational Analysis (GRA) and MOORA approaches. World Journal of Applied Economics, 3(2), 26-47.

Zarbakhshnia, N., \& Jaghdani, T. J. (2018). Sustainable supplier evaluation and selection with a novel two-stage DEA model in the presence of uncontrollable inputs and undesirable outputs: a plastic case study. The International Journal of Advanced Manufacturing Technology, 1-13. DOI: 10.1007/s00170-018-2138-z

Zarbakhshnia, N., Soleimani, H., \& Ghaderi, H. (2018). Sustainable third-party reverse logistics provider evaluation and selection using fuzzy SWARA and developed fuzzy COPRAS in the presence of risk criteria. Applied Soft Computing, 65, 307-319.

Zarbakhshnia, N., Soleimani, H., Goh, M., \& Razavi, S. S. (2019). A novel multi-objective model for green forward and reverse logistics network design. Journal of Cleaner Production, 208, 1304-1316.

Zareinejad, M., Javanmard, H., \& Arak, I. (2013). Evaluation and selection of a third-party reverse logistics provider using ANP and IFG-MCDM methodology. Life Science Journal, $10(6 s), 350-355$.

Zavadskas, E. K., Čereška, A., Matijošius, J., Rimkus, A., \& Bausys, R. (2019). Internal Combustion Engine Analysis of Energy Ecological Parameters by Neutrosophic MULTIMOORA and SWARA Methods. Energies, 12(8), 1415. 
Zhang, R., Zhang, H., \& Liu, B. (2012). Selection of reverse-logistics servicer for electronic products with fuzzy comprehensive evaluation method. Grey Systems: Theory and Application, 2(2), 207-216. 